\title{
Prophylactic management of postpartum haemorrhage in the third stage of labour: an overview of systematic reviews
}

\author{
Yuko Masuzawa $^{1 *} \mathbb{D}$, Yaeko Kataoka $^{2}$, Kana Fujii $^{2}$ and Satomi Inoue ${ }^{1}$
}

\begin{abstract}
Background: Postpartum haemorrhage is a direct cause of maternal death worldwide and usually occurs during the third stage of labour. Most women receive some type of prophylactic management, which may include pharmacological or non-pharmacological interventions. The objective of this study was to summarize systematic reviews that assessed the effects of postpartum haemorrhage prophylactic management during the third stage of labour.

Methods: We applied the guidelines for conducting an overview of reviews from the Cochrane Handbook for Systematic Reviews of Interventions. We searched MEDLINE, EMBASE, and the Cochrane Database of Systematic Reviews to identify all relevant systematic reviews of randomized controlled trials of prophylactic management of postpartum haemorrhage in the third stage of labour compared with no treatment, placebo, or another management technique. Two review authors independently extracted data and assessed methodological quality using a measurement tool to assess reviews and quality of evidence using the Grades of Recommendation, Assessment, Development, and Evaluation for primary outcomes, summarizing results narratively.
\end{abstract}

Results: We identified 29 systematic reviews: 18 Cochrane and 11 non-Cochrane. Cochrane systematic reviews were high quality, while the quality of non-Cochrane systematic reviews varied. The following techniques suggested effective, thirdstage interventions to reduce the incidence of severe postpartum haemorrhage: active management of the third stage of labour compared to physiological management, active management compared to expectant management, administration of oxytocin compared to placebo, and use of tranexamic acid compared to placebo. The following third-stage management approaches reduced the need for blood transfusion: active management compared to physiological management, active management compared to expectant management, oral misoprostol compared to placebo, and tranexamic acid compared to placebo.

Conclusions: No effective prophylactic management techniques were identified for maternal mortality. Most methods of effective prophylactic management of postpartum haemorrhage were supported by evidence; however, they were limited to low- or moderate-quality evidence, and high-quality studies are therefore needed. Outcome measures of the included systematic reviews varied. It is recommended that outcome measures in preventive postpartum haemorrhage intervention trials align with the World Health Organization guidelines.

Systematic review registration: PROSPERO: CRD42016049220.

Keywords: Postpartum haemorrhage, Third-stage labour, Prevention, Randomized controlled trial, Systematic review, Overview of systematic review

\footnotetext{
* Correspondence: 14DN013@slcn.ac.jp

${ }^{1}$ Graduate School of Nursing Science, St. Luke's International University, 10-1,

Akashi-cho, Chuo-ku, Tokyo 104-0044, Japan

Full list of author information is available at the end of the article
}

(c) The Author(s). 2018 Open Access This article is distributed under the terms of the Creative Commons Attribution 4.0 International License (http://creativecommons.org/licenses/by/4.0/), which permits unrestricted use, distribution, and reproduction in any medium, provided you give appropriate credit to the original author(s) and the source, provide a link to the Creative Commons license, and indicate if changes were made. The Creative Commons Public Domain Dedication waiver (http://creativecommons.org/publicdomain/zero/1.0/) applies to the data made available in this article, unless otherwise stated. 


\section{Background}

\section{Description of the condition}

Maternal mortality is an indicator of women's health [1]. The primary cause of maternal death in both developing and developed countries is postpartum haemorrhage (PPH) [2, 3], representing $19.7 \%$ of maternal deaths worldwide [4]. PPH is defined as blood loss $\geq 500 \mathrm{~mL}$ within the first $24 \mathrm{~h}$ after delivery [5]. The prevalence of $\mathrm{PPH}$ (blood loss $\geq 500 \mathrm{~mL}$ ) is approximately $6.0-10.0 \%$, and the prevalence of severe $\mathrm{PPH}$ (blood loss $\geq 1000 \mathrm{~mL}$ ) is approximately $1.8-3.0 \%$ in any type of delivery but varies by region in the world [6]. Representing a significant medical threat worldwide, effective strategies for the prevention of $\mathrm{PPH}$ are essential to decrease maternal mortality rates.

The period during delivery of the baby and placenta is defined as the third stage of labour and is a critical time for the occurrence of $\mathrm{PPH}$ [7]. After the third stage of labour, haemostasis processes are activated. Contraction of the uterine muscles is the primary physiological process for postpartum haemostasis and results from the actions of oxytocin and prostaglandins. The uterine smooth muscles are spiral structures that extend in all directions. The spiral vessels of the uterus are compressed by the contractions of uterine muscles, which lead to decreased blood flow [8]. Moreover, blood clotting and fibrinolytic factors increase in pregnant women [9]. The failure of these physiological mechanisms during postpartum haemostasis is one of the causes of PPH. Events that may influence $\mathrm{PPH}$ include uterine atony, cervical or vaginal lacerations, retention of the placenta, and coagulation disorders [10, 11]. Among these, the most prominent cause of $\mathrm{PPH}$ is uterine atony (34.0\%) [12]. PPH has 19 identified risk factors: age $\geq 35$ years [13], body mass index $\geq 30 \mathrm{~kg} / \mathrm{m}^{2}$ [14], Pacific island or Asian ethnicity [14, 15], parity of three or more [13], primiparity $[12,15,16]$, multiple birth $[12,15$, 17], history of PPH [15], hypertensive disorders [14], pre-eclampsia $[14,15]$, placenta previa $[14,17]$, placental abruption [17], retained placenta [16], induction of labour [13-15], prolonged labour [12, 15, 16], obstructed labour [12], episiotomy $[14,15]$, instrumental labour [14, 15], caesarean section [13], and gestational age at delivery $<37$ weeks $[13,17]$.

\section{Description of the intervention}

Given that PPH usually occurs during and after the third stage of labour [6], primary guidelines recommend active management of this stage. The main component of effective $\mathrm{PPH}$ prophylactic management is the administration of uterotonics $[5,10,18-20]$. Active management is a set of prophylactic interventions consisting of the following components: administration of uterotonics after delivery, early umbilical cord clamping, controlled cord traction for earlier delivery of the placenta, and in certain cases, uterine massage [5].
In contrast with active management, expectant and physiological managements are "hands-off" techniques involving no administration of prophylactic uterotonic agents and delivery of the placenta only through maternal efforts [5]. The World Health Organization (WHO) guideline for preventing $\mathrm{PPH}$ recommend the following interventions: use of uterotonics during the third stage of labour for all births, use of oxytocin (10 IU) as the uterotonic drug, controlled umbilical cord clamping in settings where skilled birth attendants are available, and late cord clamping [5]. Moreover, the National Institute for Health and Care Excellence's guidelines were revised in 2014, including a change in the definition of active management of the third stage of labour. The ideal timing of cord clamping, as one component of active management, was changed from early to late, as evidence indicated that late cord clamping did not negatively impact maternal outcomes and had benefits for the neonate [18].

The effectiveness of some prophylactic management techniques for $\mathrm{PPH}$ in the third stage of labour has been evaluated in Cochrane systematic reviews. Active management of the third stage of labour was evaluated in comparison with expectant management [21]. Early cord clamping plus controlled cord traction, as one component of active management, is believed to prevent retained placenta and a prolonged third stage of labour. The effectiveness of the timing of cord clamping [22] and controlled cord traction [23] has been recently evaluated.

Other prophylactic interventions were considered in this overview, including use of uterotonic drugs, use of hemostatic agents and uterine massage. For uterotonic drugs, the following were considered as representative methods of augmenting uterine contractions: oxytocin [24-29], prostaglandin [30-32], and ergot alkaloid [33]. Oxytocin is a naturally occurring hormone that stimulates uterine contractions [34] and is commonly used as a uterotonic. The half-life of oxytocin is short (4-7 $\mathrm{min})$ [35]; therefore, both repeated doses and continuous infusion are acceptable [20]. Prostaglandin is also a naturally occurring hormone; misoprostol, a prostaglandin E1 analogue, can be used orally, sublingually, vaginally, or rectally [36]. Furthermore, misoprostol has mild side effects, such as shivering and pyrexia [37]. Ergot alkaloids act to contract the myometrium through calcium channel mechanisms; however, this also increases the incidence of side effects such as hypertension [38]. A survey examining the use of prophylactic uterotonic agents in 28 countries noted that $95.3 \%$ of deliveries used prophylactic uterotonics for the prevention of $\mathrm{PPH}$, and the most commonly used uterotonic agent was oxytocin [13].

\section{Why it is important to do this review}

Many prophylactic management techniques for PPH in the third stage of labour have been evaluated in 
systematic reviews of randomized controlled trials (RCTs). The extant systematic reviews of evidence from RCTs regarding prophylactic management of $\mathrm{PPH}$ in the third stage of labour have never been summarized. Furthermore, many clinical guidelines for preventing $\mathrm{PPH}$ [18-20] were published and are reflected in these systematic reviews. This overview will allow the many readers (such as clinicians, midwives, policy makers, and consumers) to quickly assess a range of evidence about prophylactic management techniques for $\mathrm{PPH}$ and utilize this information for making decisions. Regarding the application to research, through summarizing the effectiveness of interventions by outcomes, this overview will also provide a set of outcome measures that are clinically meaningful that can be applied to future studies.

\section{Objectives}

The objective of this overview was to:

- provide a narrative summary of systematic reviews of RCTs;

- provide the effectiveness of prophylactic management of PPH during the third stage of labour of any type of delivery (vaginal or caesarean section) in terms of outcome measures including maternal mortality, blood loss greater than $1000 \mathrm{~mL}$, and use of blood transfusion.

\section{Methods}

In this overview, we applied the guidelines for conducting an overview of reviews from the Cochrane Handbook for Systematic Reviews of Interventions [39] and adhered to the systematic reporting guidelines of the preferred reporting items for systematic reviews and meta-analysis (PRISMA) statement [40]. The PRISMA checklist is shown in Additional file 1. Our review protocol was registered with the International Prospective Register of Systematic Reviews (PROSPERO) (CRD42016049220).

\section{Criteria for considering included review Type of reviews}

In this overview, we included published systematic reviews of RCTs in which prophylactic management of $\mathrm{PPH}$ in the third stage of labour was administered after delivery. We excluded reviews that were not systematic reviews of RCTs and those that were only abstracts. When the identified Cochrane review was an updated review with a previous version, we also excluded the previous version and only included the updated version.

\section{Type of participants}

The review subjects were women who delivered vaginally or by caesarean section. We recognize that the risk of $\mathrm{PPH}$ for vaginal delivery or caesarean section may vary, but we included both delivery methods because some of the reviews presented their results regardless of the mode of delivery.

\section{Type of intervention and comparisons}

We included any prophylactic managements of $\mathrm{PPH}$ in the third stage of labour and divided them into the following subgroups.

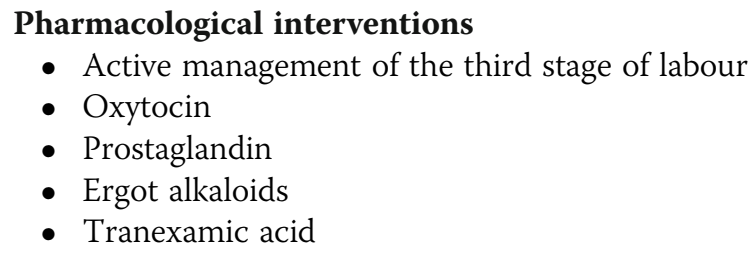

\section{Non-pharmacological interventions \\ - Early umbilical cord clamping \\ - Controlled cord traction \\ - Uterine massage}

We excluded non-prophylactic management. We compared these interventions with placebo, no treatment, contrasting interventions, or other interventions.

\section{Type of outcomes}

We searched for the three critical outcomes proposed in the WHO's recommendations for the prevention and treatment of postpartum haemorrhage guidelines [5].

- Maternal mortality

- Blood loss greater than $1000 \mathrm{~mL}$

- Use of blood transfusion

\section{Search strategy}

A comprehensive search was conducted for relevant reviews published in any language in MEDLINE (via EBSCO, 11 October 2016), EMBASE (1980 to 11 October 2016), Cochrane Database of Systematic Reviews (issue 10 of 12 October 2016), and Database of Abstracts of Reviews of Effect (Cochrane library issue 2 of 4 April 2015), using the search terms "postpartum haemorrhage" and "prevention." Systematic review search filters in clinical evidence [41] were used to search MEDLINE and EMBASE. The search strategy is detailed in Additional file 2.

\section{Selection of systematic reviews}

Two authors (YY, KF) independently assessed all potential systematic reviews that resulted from our search strategy for inclusion in the present review. We resolved any disagreement through discussion and/or by consulting the third author (YK). 


\section{Data extraction}

A predefined form was used for data extraction, which included the following sections: study design, participants, experimental intervention, comparison intervention, outcomes, quality of the review, and pooled effect sizes for main outcome measures in metanalyses. When an included review did not identify the number of outcome events or was not meta-analysed, we verified the primary sources included in the review and then performed meta-analysis ourselves using Review Manager 5.3 [42]. We assessed each study's statistical heterogeneity using $I^{2}$ statistics. Where heterogeneity was observed $\left(I^{2}>50 \%\right)$, we conducted a random-effects model for combining data. A fixed-effect model was used if the heterogeneity indicated non-importance $\left(I^{2}<50 \%\right)$. We presented a risk ratio with $95 \%$ confidence intervals (CI) about dichotomous data.

Two review authors (YM, SI) independently extracted data from the reviews using the data extraction form. We entered data into the Review Manager software 5.3 [42] and GRADEpro GDT software [43] and verified accuracy.

\section{Quality of evidence in included reviews}

Quality of evidence in the included reviews was examined using the Grades of Recommendation, Assessment, Development and Evaluation (GRADE) approach [44] for outcomes. The GRADE approach is a system that evaluates quality of evidence, which is assessed on a 4-point scale ("very low," "low," "moderate," and "high") in five domains: (1) study limitations, (2) inconsistency of results, (3) indirectness of evidence, (4) imprecision, and (5) publication bias [44]. We assessed "study limitation" by using the approach of the Cochrane risk of bias tool [39]. If the original study did not assess the risk of bias, we assessed the risk of bias on low, high, or unclear for: (1) selection biases, (2) performance bias, (3) detection bias, (4) attrition bias, (5) reporting bias, and (6) other potential sources of bias [39]. When we assessed the domain of the "imprecision" of the GRADE approach, we focused on the $95 \%$ CI around the difference in effect between intervention and comparison. We concluded that the imprecision was not serious when: (1) the $95 \%$ CI did not include the RR of 1.0 and included appreciable benefit or harm ( $R R$ of under 0.75 or over $1.25)$; and (2) the total event number and the optimal information size were enough [45]. We used the GRADEpro GDT software's [43] "summary of findings" tables for each outcome.

\section{Assessment of methodological quality of included reviews} The review authors (YM, KF, YK) independently assessed the quality of evidence and methodological quality of the included reviews using the instrument: a measurement tool to assess reviews (AMSTAR) [46].
The AMSTAR tool [46] consists of 11 criteria for measuring the methodological quality of systematic reviews, which is determined by a questionnaire with 11 items that asks reviewers to answer "yes," "no," "cannot answer," or "not applicable." We resolved discrepancies through discussion.

\section{Data synthesis}

We provided a narrative summary of the individual review results for each outcome displayed in tables and figures that included characteristics of each review, AMSTAR ratings and outcomes using GRADE. Although we planned to present the data divided by the mode of delivery, almost all original reviews including vaginal and caesarean section deliveries presented the data together, not separately. Therefore, we did not provide the review result for each outcome divided by the delivery mode.

\section{Results}

\section{Description of included reviews}

Figure 1 is a flow diagram of the selection process. A total of 291 studies were identified from the database search. After removing duplicates, 171 studies remained. A total of 135 titles and abstracts were excluded because they were not systematic reviews or did not examine prophylactic management of PPH. There were 46 full-text studies remaining; of these, 17 were excluded because they did not include prophylactic management, were not systematic reviews of RCTs, or were only abstracts. The excluded studies list is detailed in Additional file 3. A final sample of 29 studies met the inclusion criteria.

Of the 29 systematic reviews, 18 Cochrane systematic reviews and 11 non-Cochrane systematic reviews were analysed: five studies examining active management of the third stage of labour [21, 23, 47-49], eight examining the use of oxytocin $[24-29,50,51]$, seven examining the use of prostaglandin [30-32, 52-55], one examining the use of ergot alkaloids [33], five examining tranexamic acid [56-60], one examining timing of umbilical cord clamping [22], one examining uterine massage [61], and one examining breastfeeding or nipple stimulation [62]. The participants in these reviews had undergone caesarean or vaginal deliveries. Table 1 shows the characteristics of these reviews.

\section{Quality of included reviews}

AMSTAR [46] ratings representing the quality of systematic reviews are displayed in Table 2. The methodological quality of 16 Cochrane systematic reviews was high, with scores ranging from 10 to 11 . The 10 non-Cochrane systematic review scores varied from 1 to 7. The majority of non-Cochrane reviews did not list the included and excluded studies and/or did not consider the quality of included studies. 


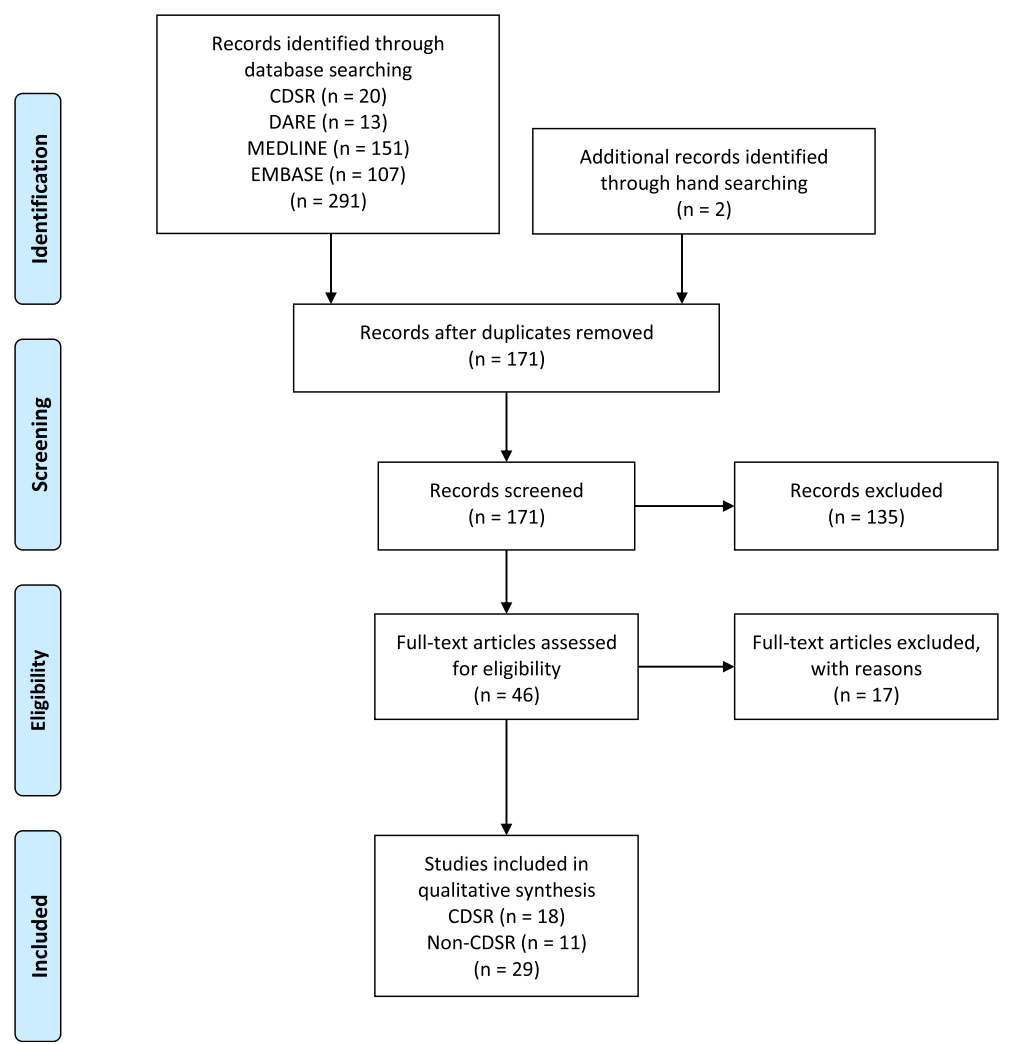

Fig. 1 Study flow diagram using the PRISMA 2009 flow diagram

\section{Quality of evidence in included reviews}

Quality of evidence of the included reviews, as measured using the GRADE approach [44], varied by review and is displayed in Tables 3, 4, and 5. The risk of biased scores or imprecision was serious; therefore, the quality of evidence was low to moderate. For the rating of limitations of GRADE approach [44], we provided the result of assessing the risk of bias of the included reviews which did not provide the risk of bias for the included RCTs [48, 52-54] in Additional file 4.

\section{Effect of interventions for maternal mortality}

We identified seven reviews that examined maternal mortality: two regarding active management of the third stage of labour [23, 47], one examining the use of oxytocin [51], three examining the use of prostaglandins [30, 32, 52], and one examining nipple stimulation [62]. Table 3 portrays the effects of these management techniques.

\section{Active management versus contrasting management}

In the comparison of active management during the third stage of labour with and without controlled cord traction, there was no significant difference between the groups: $(31 / 11,616$ versus $20 / 11,616$; relative risk $(R R)=1.55,95 \%$ confidence interval $(\mathrm{CI})=0.88$ to $2.72 ; 1 \mathrm{RCT} ; 23,232$ women) [47] and (34/13,650 versus $25 / 13,650$; $R R=1.22$,
95\% CI $=0.55$ to $2.74 ; 2$ RCTs; 27,300 women; heterogeneity; $I^{2}=32 \%$ ) [23].

\section{Oxytocin versus no treatment}

There were no cases reporting maternal deaths related to oxytocin injection. Therefore, the effect of an oxytocin injection (10 IU) in the thigh compared to no treatment could not be estimated [51].

\section{Prostaglandin versus placebo}

In the comparison of misoprostol (>600 $\mu \mathrm{g})$ versus placebo, there was no difference between the groups $(8 / 11,153$ versus $3 / 11,125 ; \mathrm{RR}=2.0,95 \% \mathrm{CI}=0.68$ to 5.83 ; 5 RCTs; 22,278 women; heterogeneity; $I^{2}=0 \%$ [52] and (6/4646 versus $1 / 4707$; $R R=2.70,95 \% C I=0.72$ to 10.11 ; 10 RCTs; 9333 women; heterogeneity; $I^{2}=0 \%$ ) [30]. There was also no difference between the groups comparing oral misoprostol $(600 \mu \mathrm{g})$ with placebo or no uterotonic use (2/1975 versus $1 / 1990 ; \mathrm{RR}=1.46,95 \% \mathrm{CI}=0.24$ to $8.81 ; 3$ RCTs; 3965 women; heterogeneity; $I^{2}=29 \%$ ) [32].

\section{Nipple stimulation versus no treatment}

In the comparison of breastfeeding immediately after delivery versus no breastfeeding or nipple stimulation, no significant difference was found between the groups 


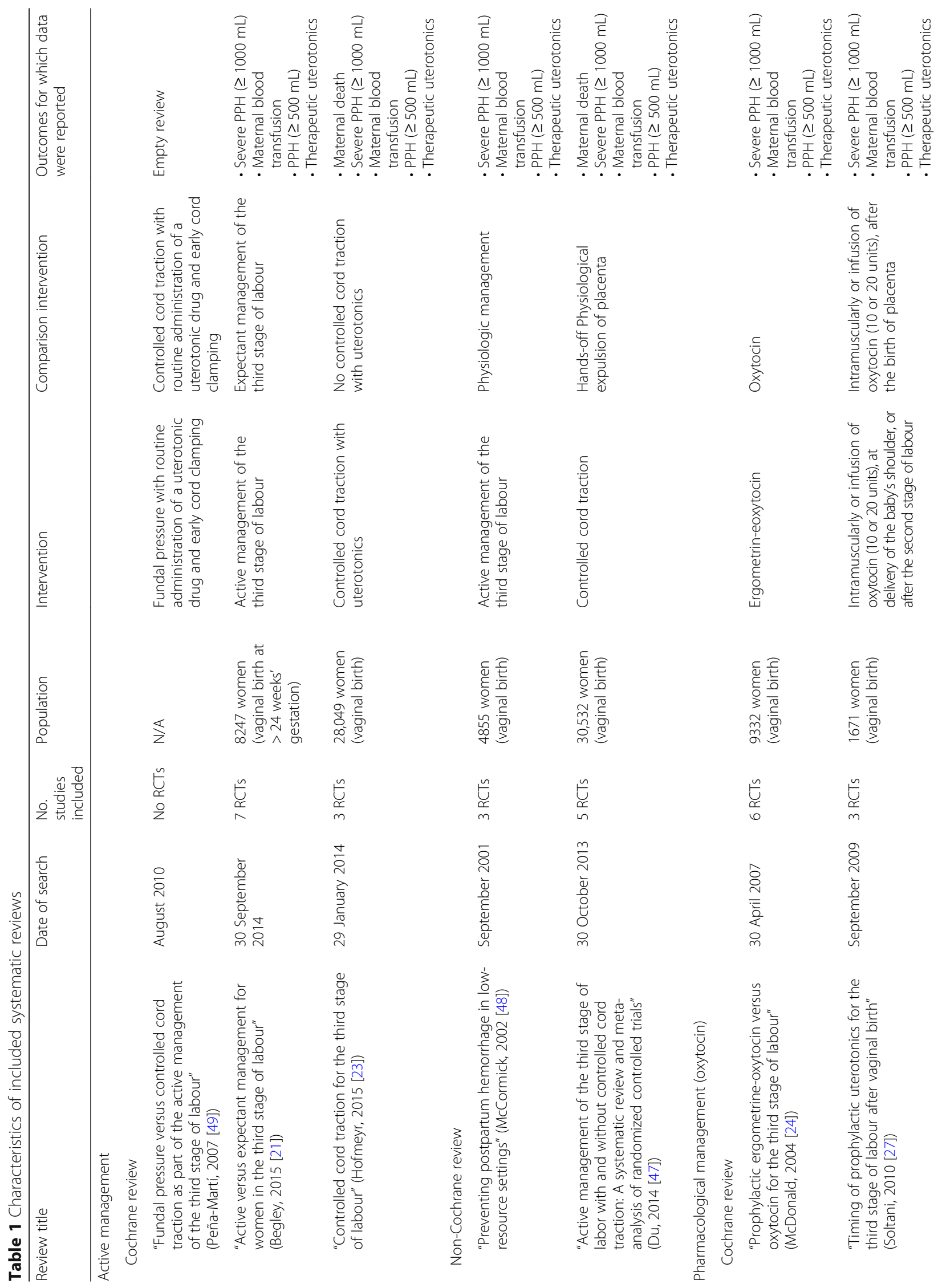




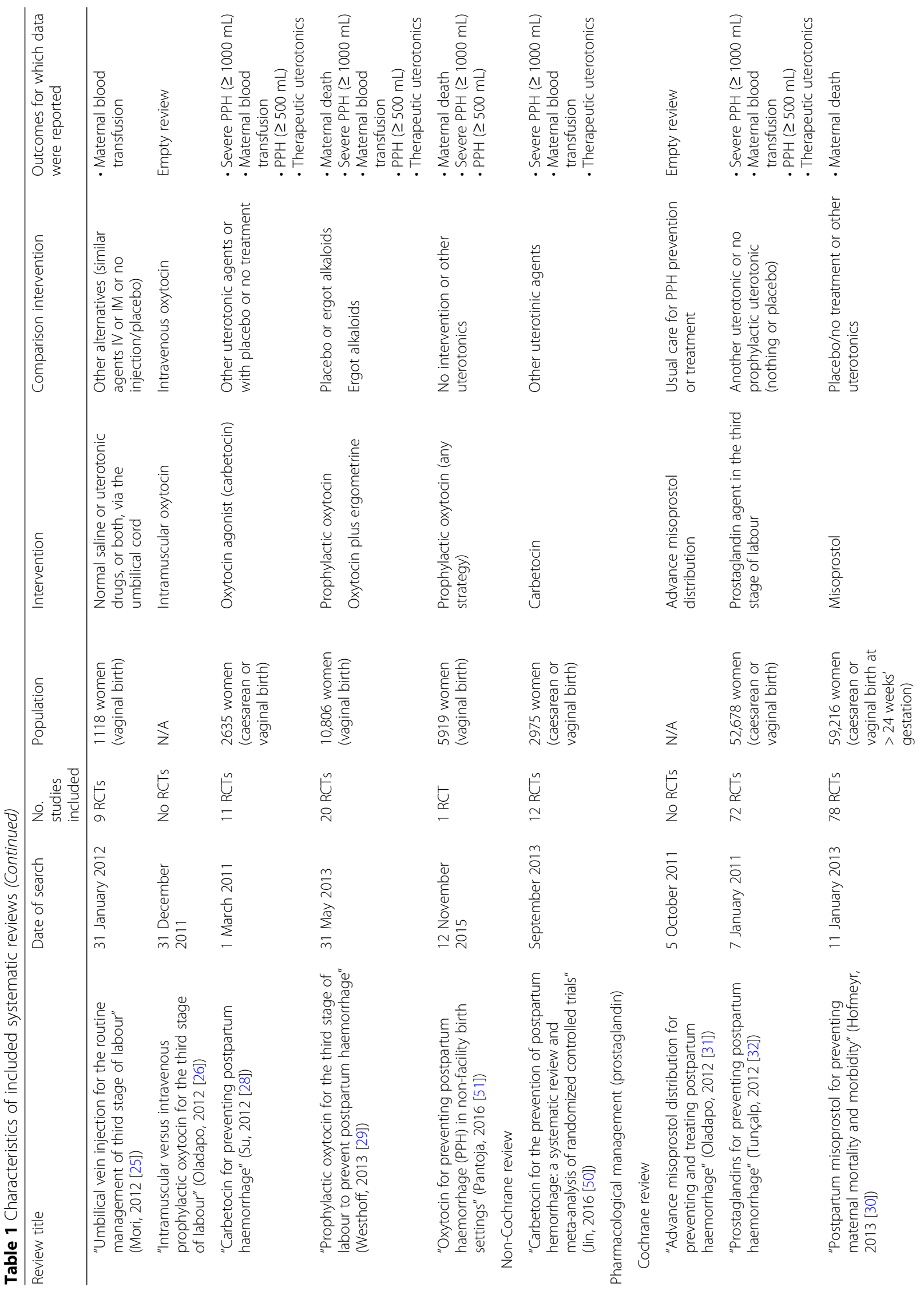




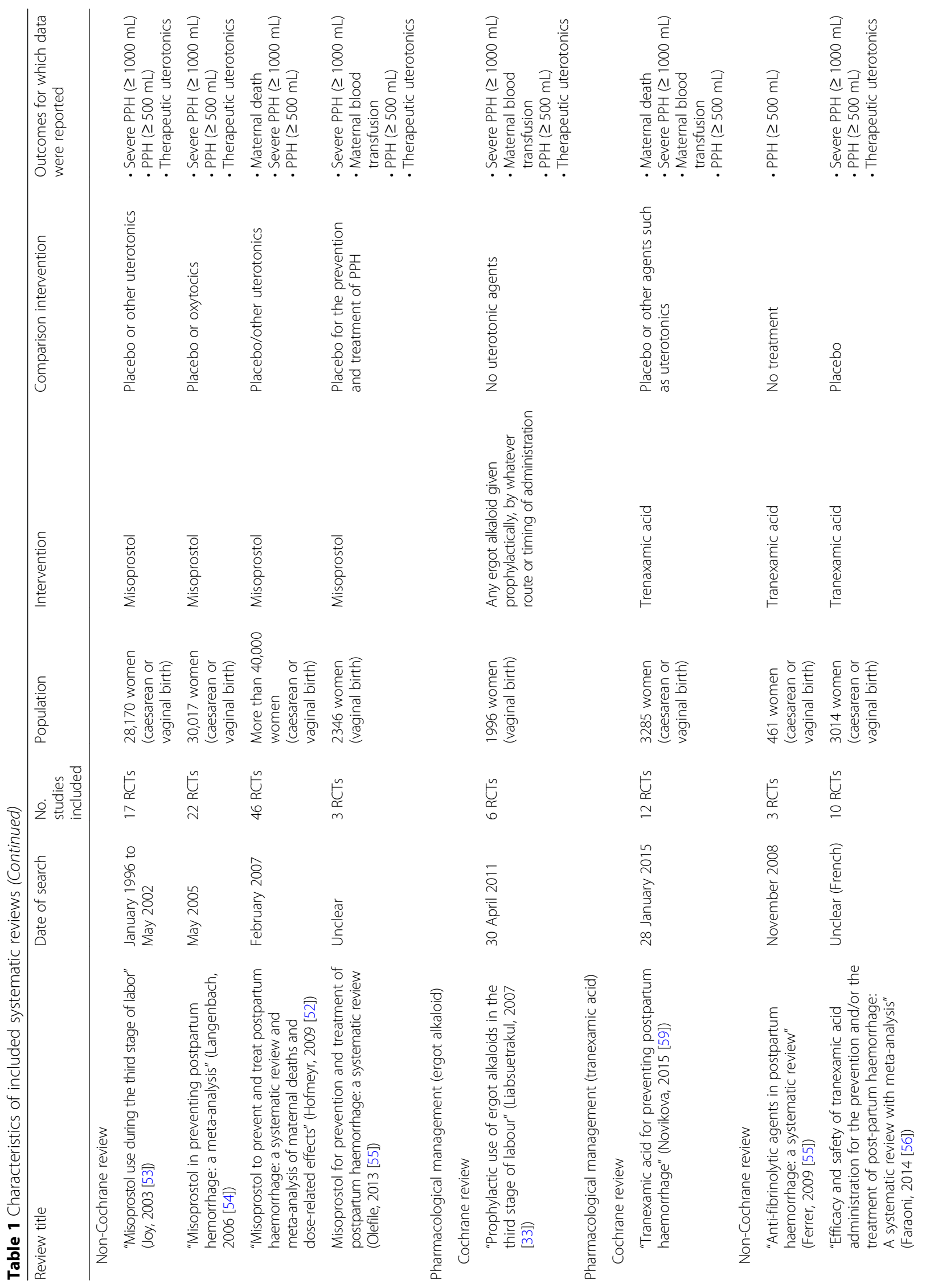




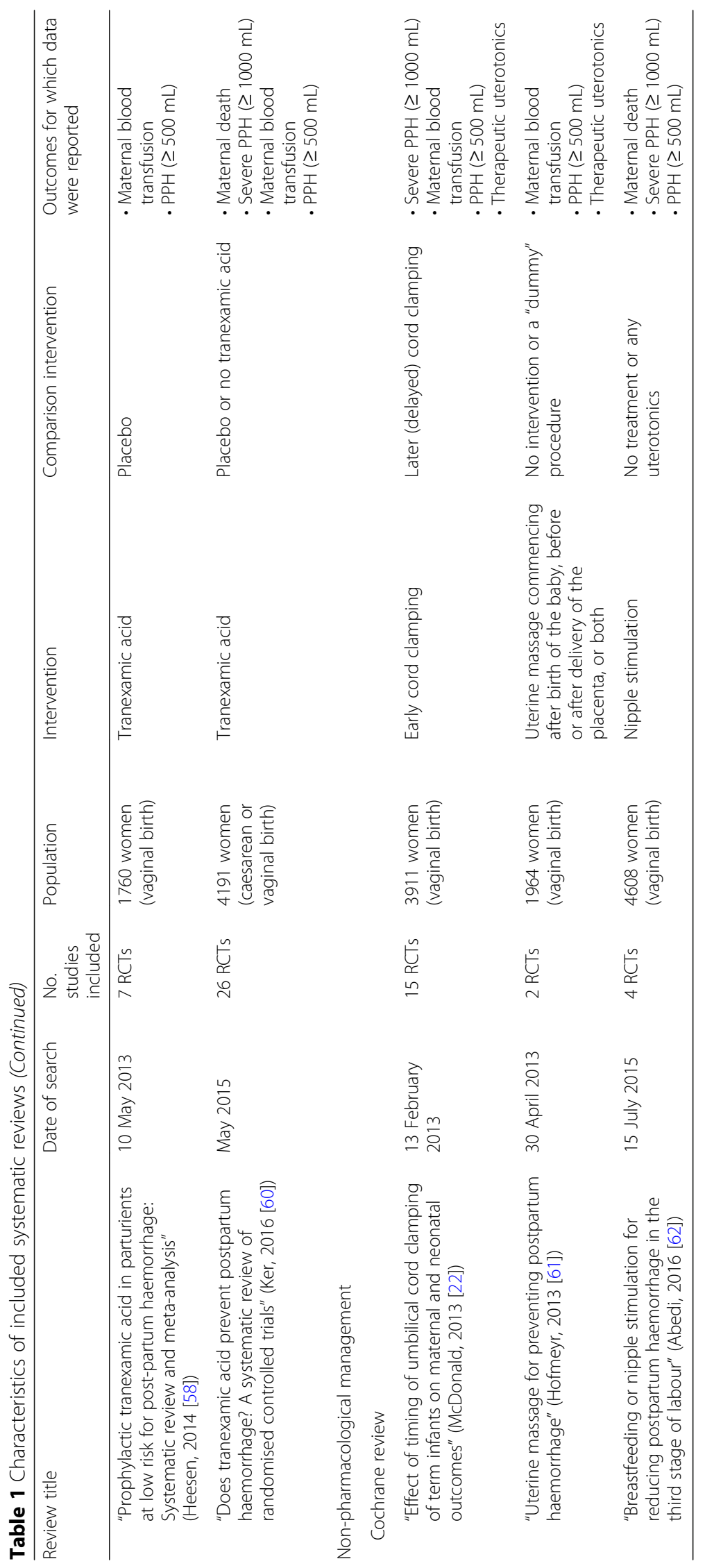




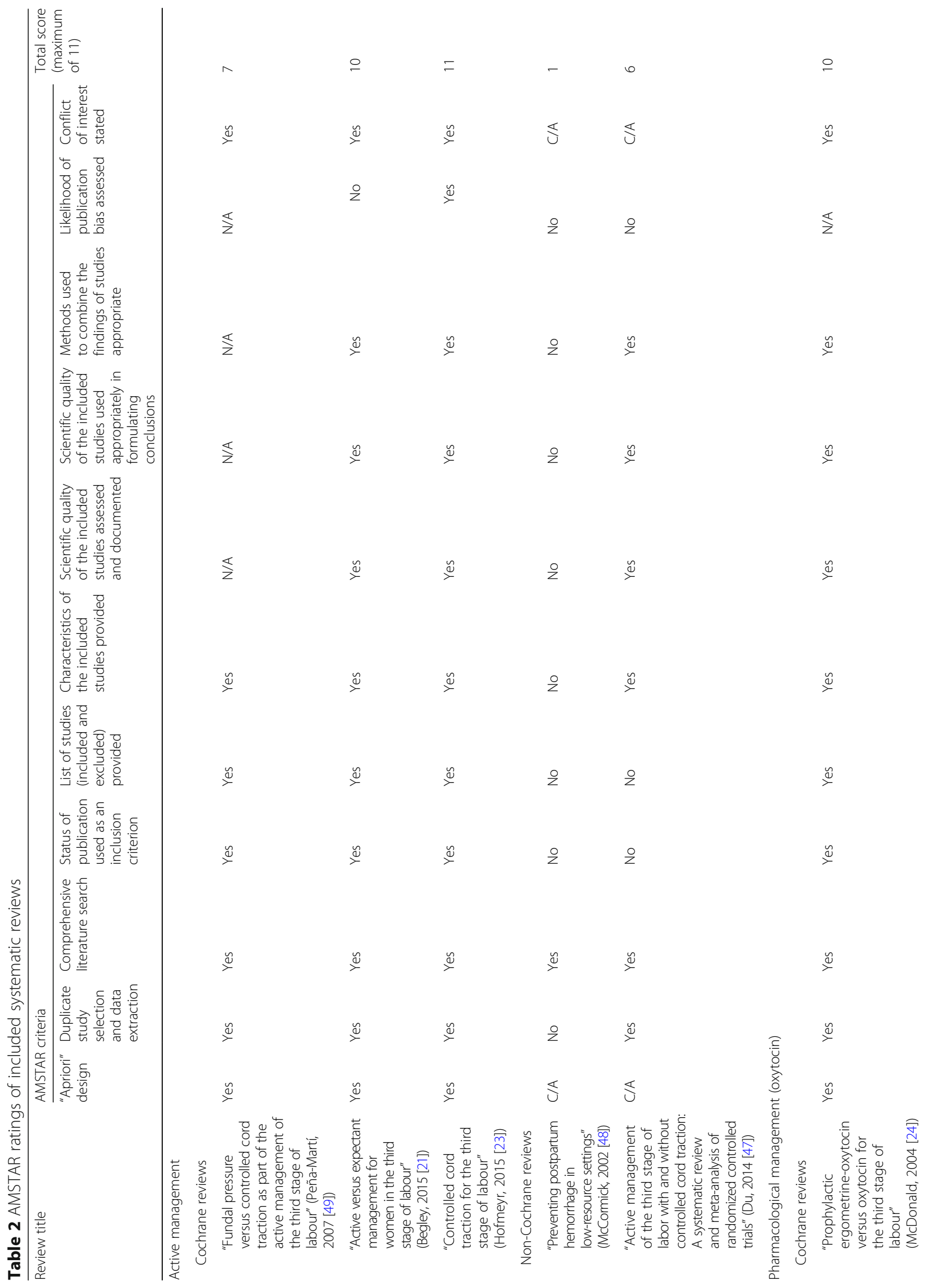




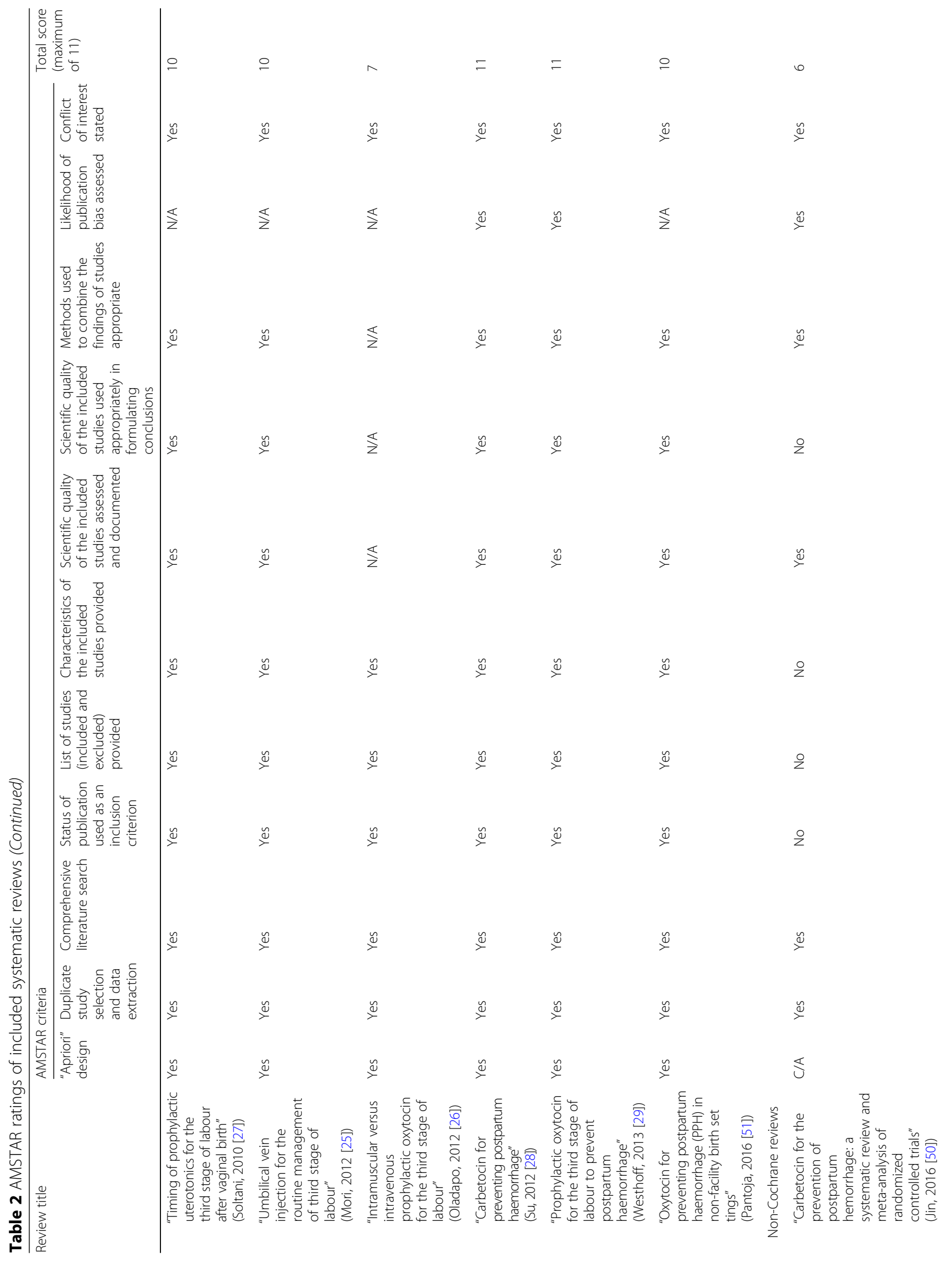




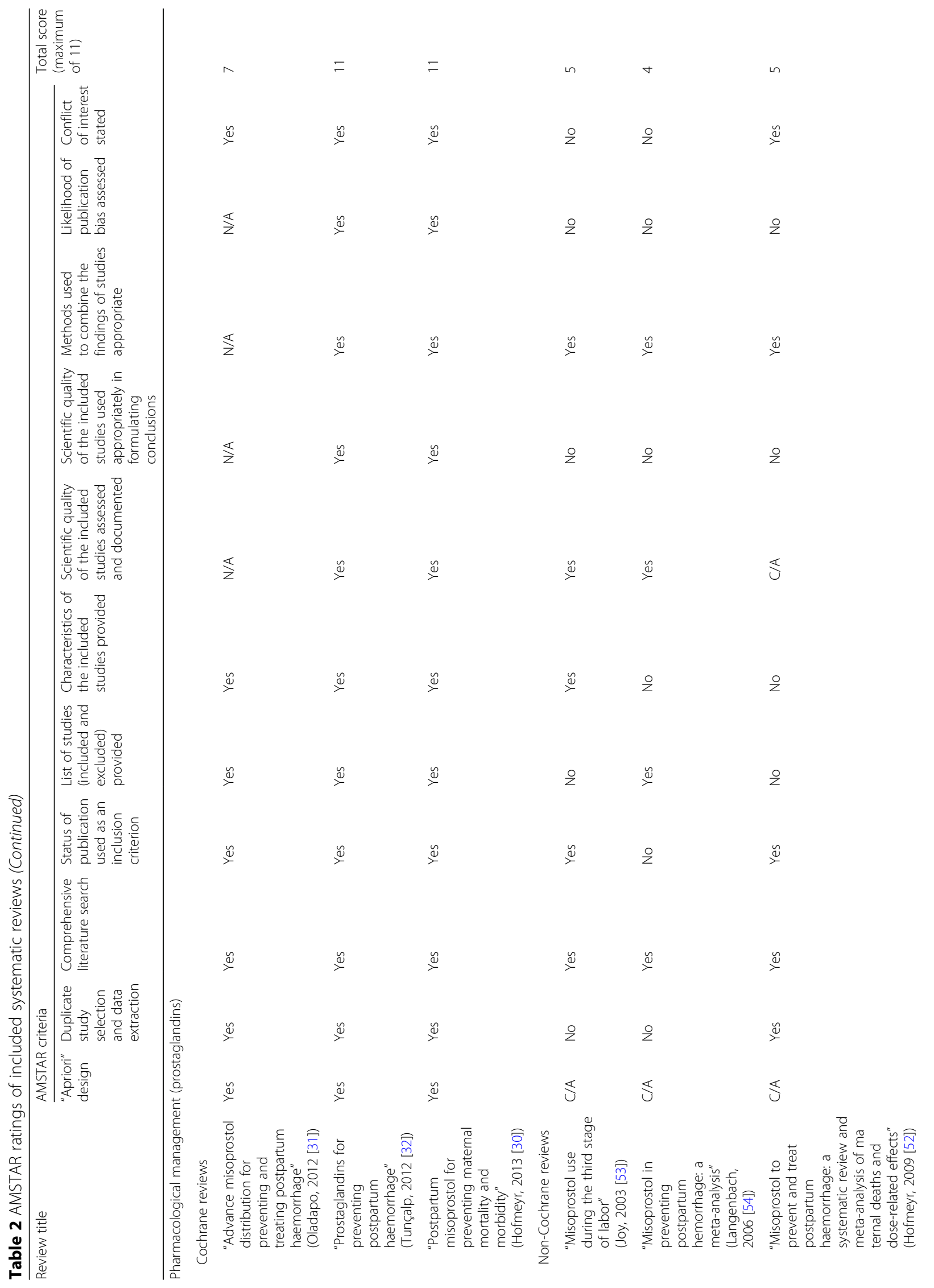




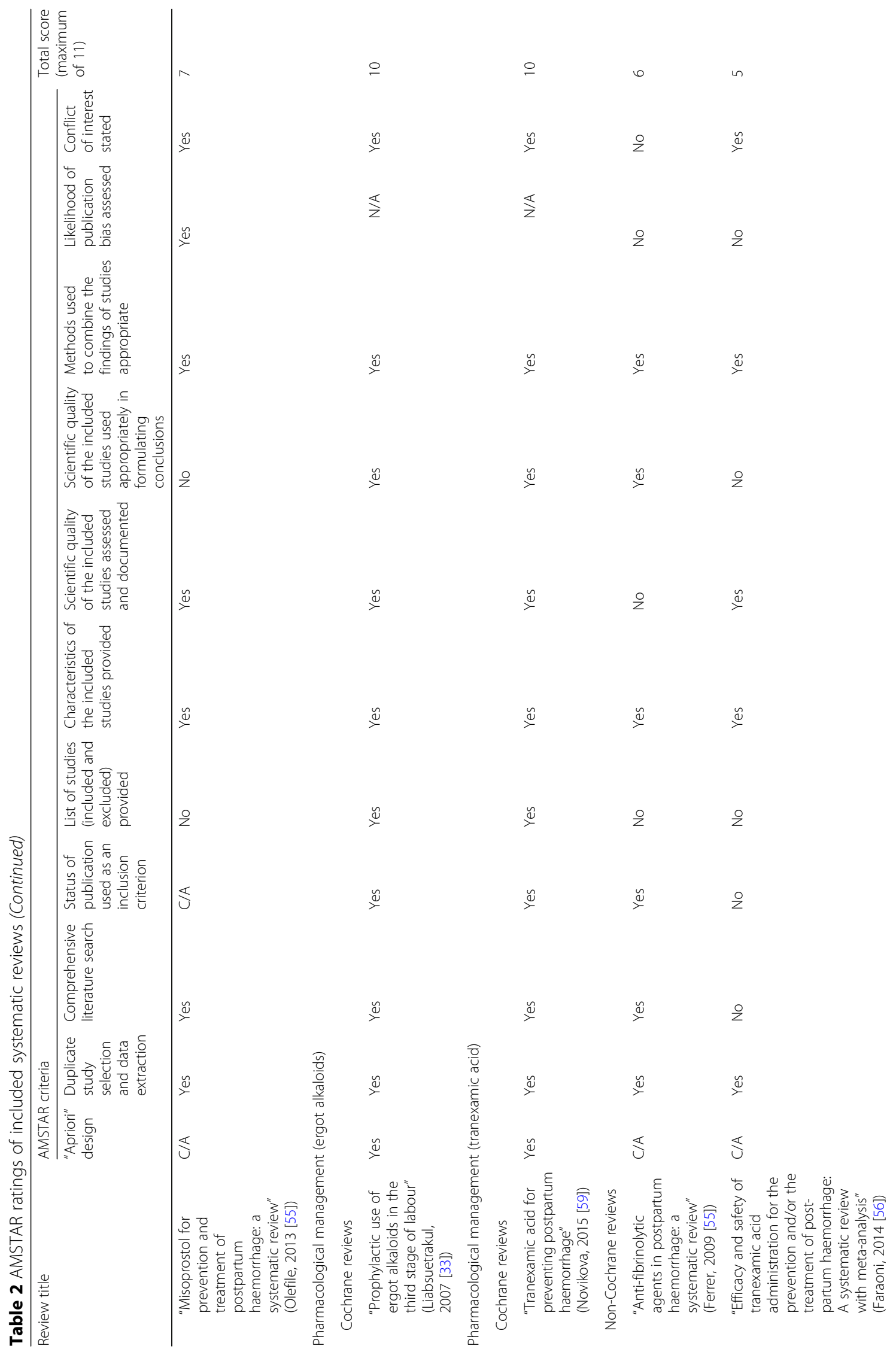




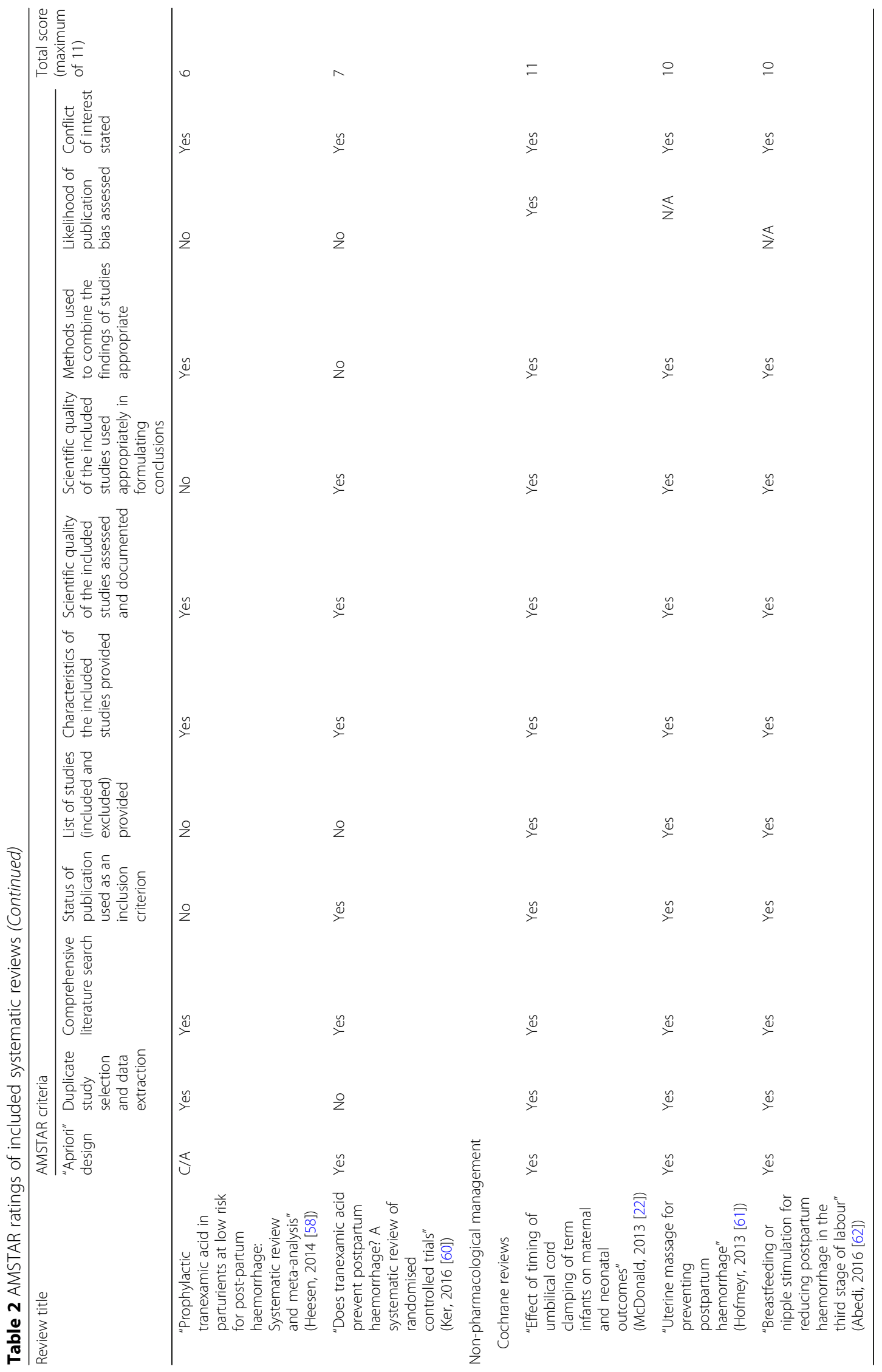




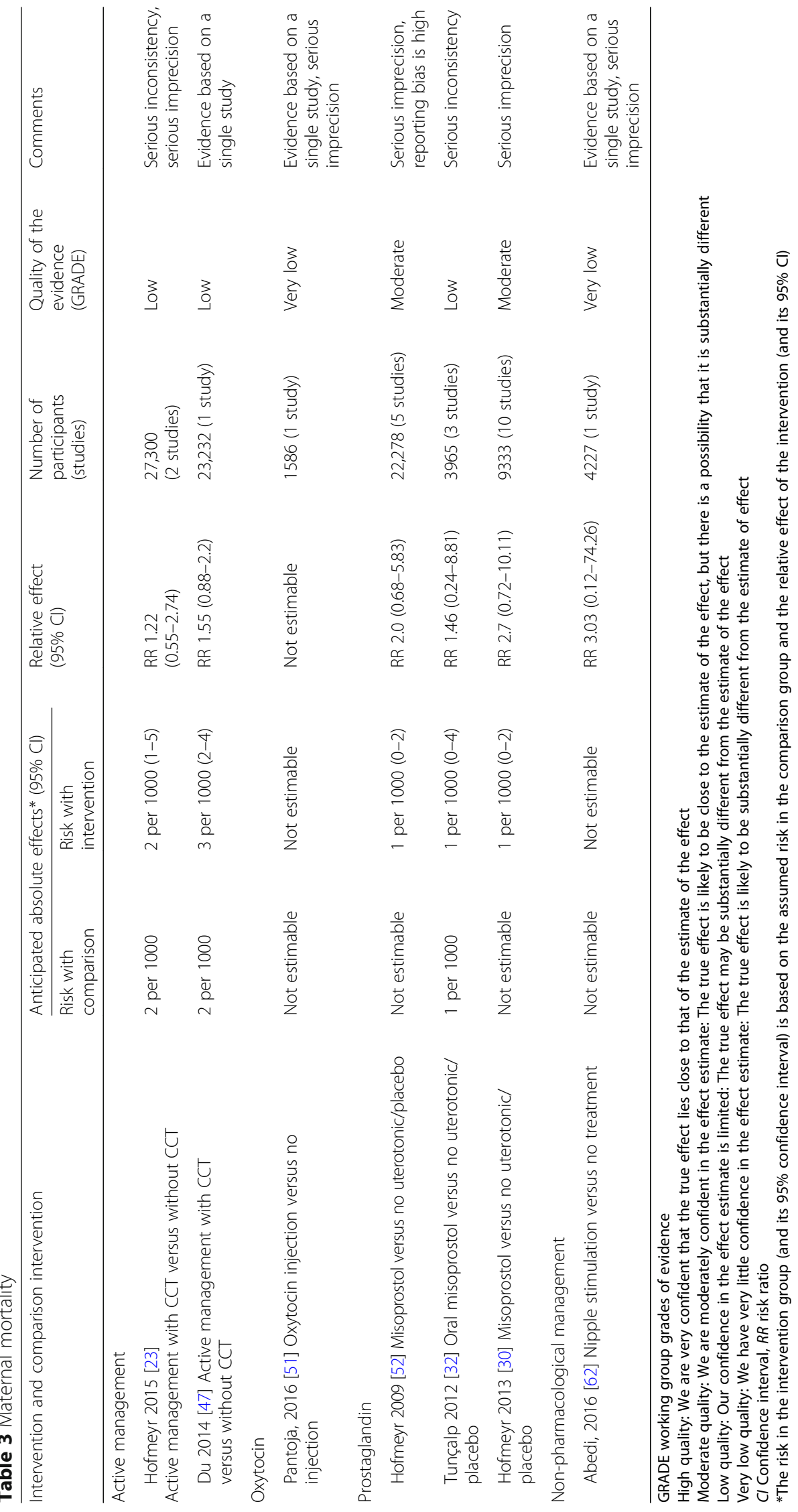




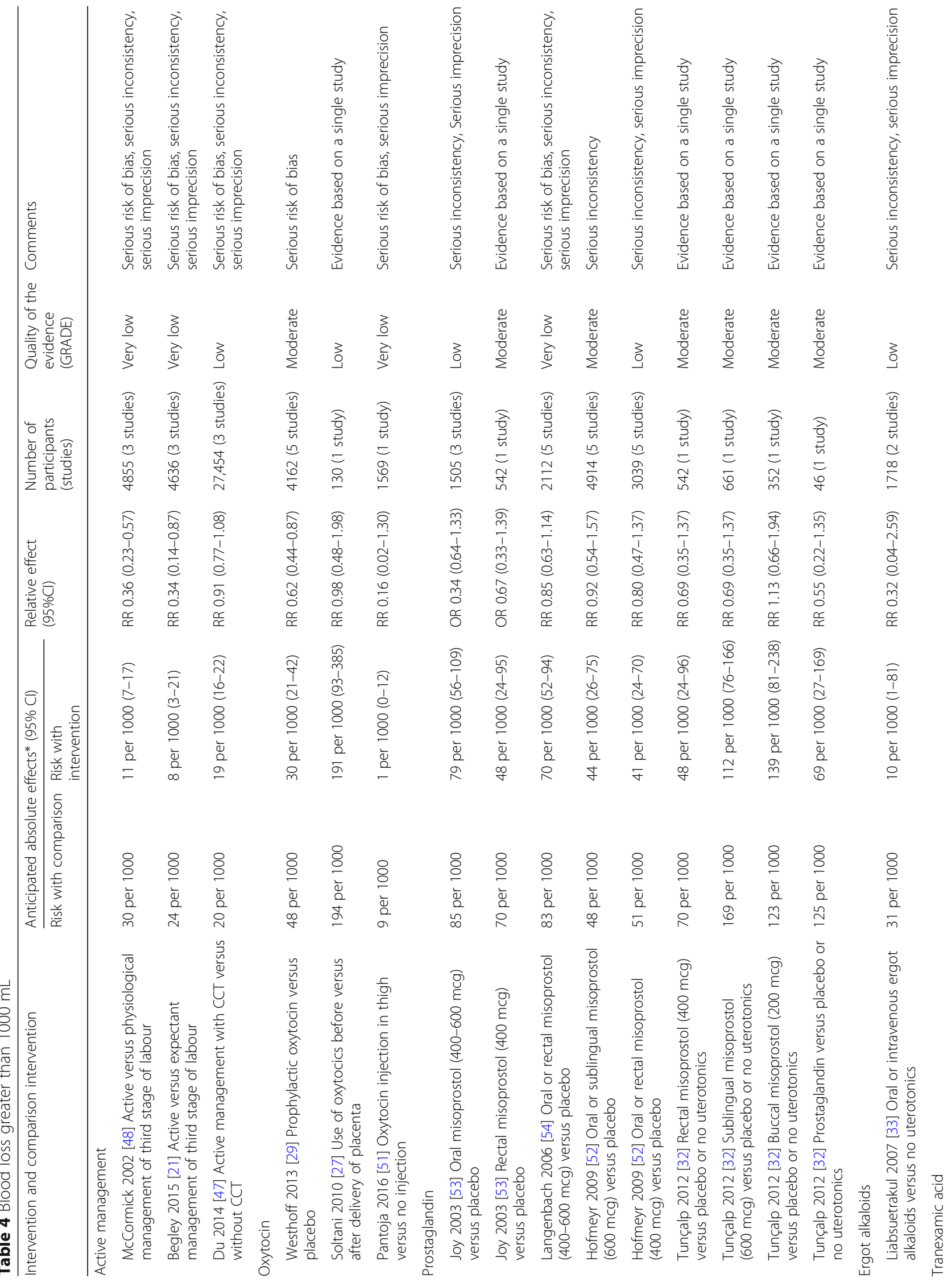




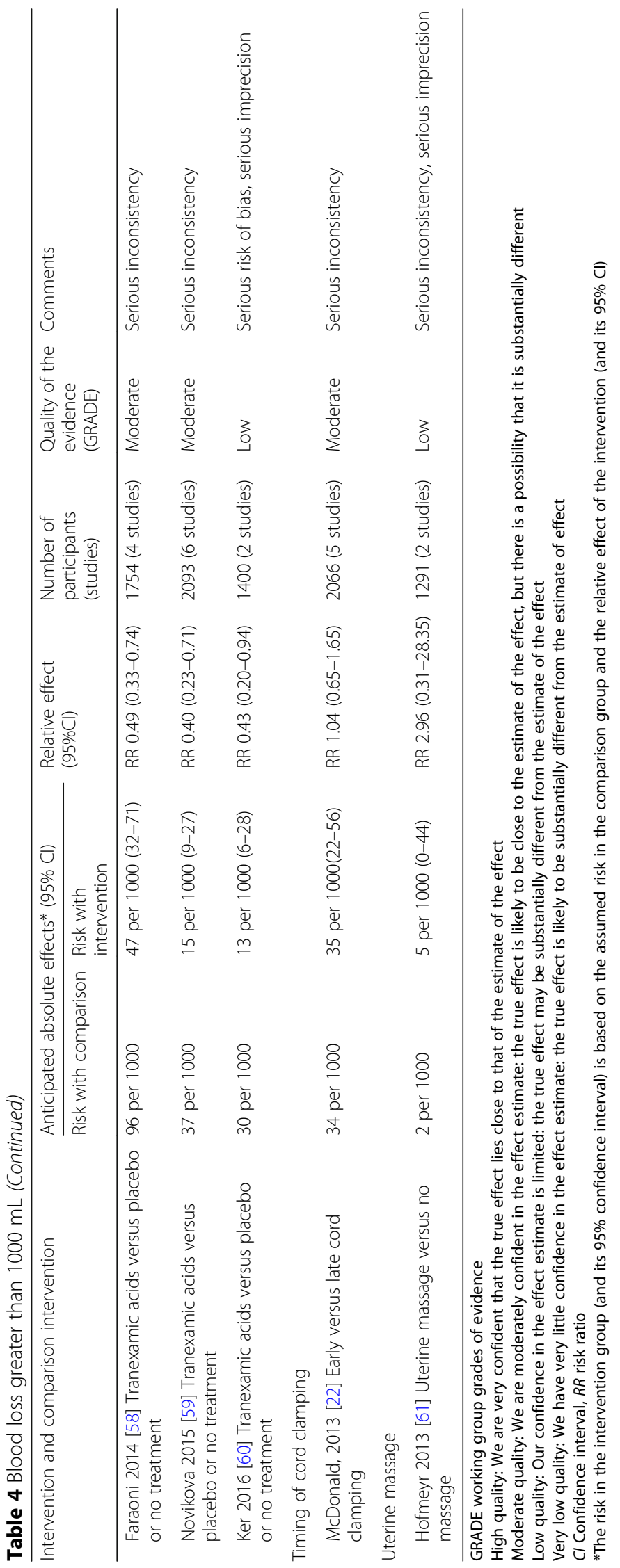




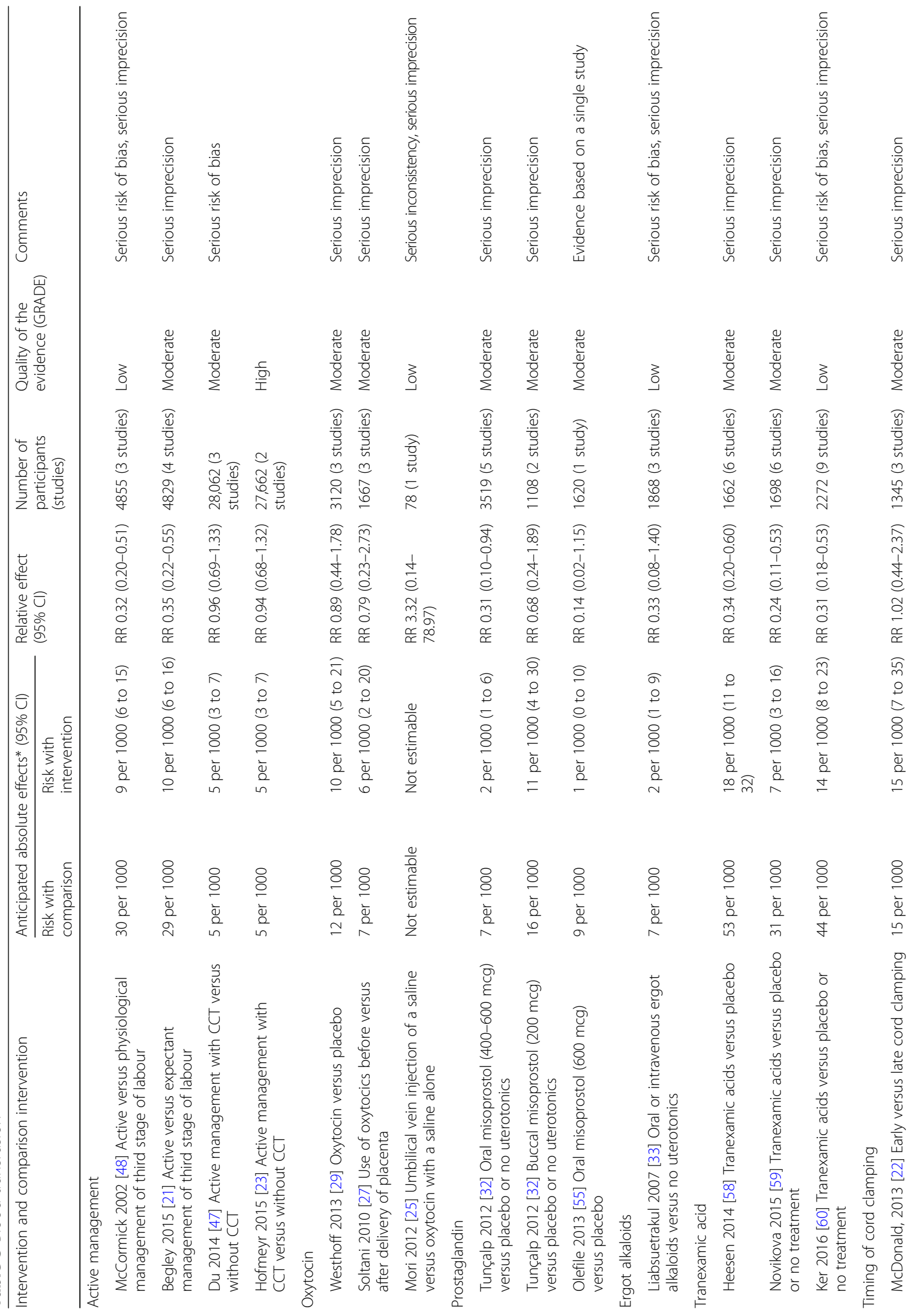




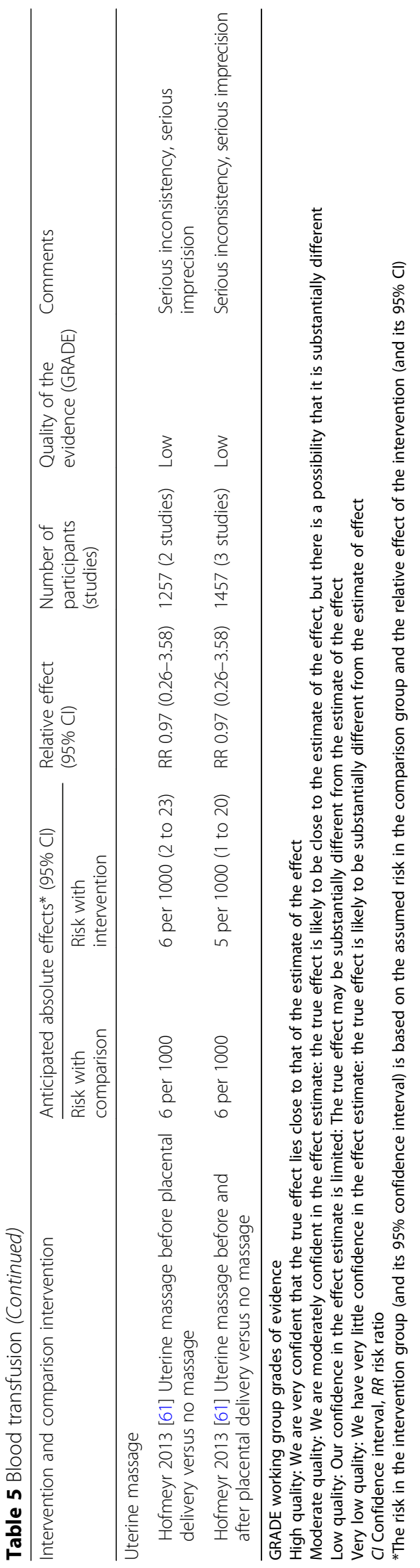


$(1 / 2104$ versus $0 / 2123 ; \mathrm{RR}=3.03,95 \% \mathrm{CI}=0.12$ to 74.26 ; 1 RCT; 4227 women) [62].

Effect of interventions for blood loss greater than $1000 \mathrm{~mL}$ A total of 20 reviews examining blood loss $>1000 \mathrm{~mL}$ were identified: four regarding active management of the third stage of labour [21, 23, 47, 48], six examining the use of oxytocin $[24,27-29,50,51]$, four examining the use of prostaglandins [32, 52-54], one examining the use of ergot alkaloids [33], three examining the use of tranexamic acid $[56,59,60]$, one examining the timing of clamping umbilical cord [22], and one examining uterine massage [61]. Table 4 only displays interventions that compared the intervention with placebo or contrasting management.

\section{Active management versus contrasting management}

Compared to physiological or expectant management, active management resulted in a significant reduction in severe $\mathrm{PPH}(26 / 2421$ versus $72 / 2434 ; \mathrm{RR}=0.36,95 \%$ $\mathrm{CI}=0.23$ to $0.57 ; 3 \mathrm{RCTs} ; 4855$ women; heterogeneity; $\left.I^{2}=55 \%\right) \quad$ [48] and $(21 / 2299$ versus 57/2337; average $\mathrm{RR}=0.34,95 \% \mathrm{CI}=0.14$ to $0.87 ; 3 \mathrm{RCTs} ; 4636$ women; heterogeneity; $I^{2}=60 \%$ ) [21]. For the comparison of active management in the third stage of labour with and without controlled cord traction, there was no significant difference between the groups (256/13,727 versus 281/13,727; $\mathrm{RR}=0.91,95 \% \mathrm{CI}=0.77$ to $1.08 ; 3 \mathrm{RCTs} ; 27,454$ women; heterogeneity; $\left.I^{2}=0 \%\right)$ [47] and $(256 / 13,727$ versus $281 /$ 13,$727 ; \mathrm{RR}=0.91,95 \% \mathrm{CI}=0.77$ to $1.08 ; 3 \mathrm{RCTs} ; 27,454$ women; heterogeneity; $I^{2}=0 \%$ ) [23].

\section{Oxytocin versus placebo}

Prophylactic use of oxytocin showed a significant reduction in severe PPH compared to a placebo $(52 / 2367$ versus $87 / 1795 ; \mathrm{RR}=0.62,95 \% \mathrm{CI}=0.44$ to $0.87 ; 5 \mathrm{RCTs}$; 4162 women; heterogeneity; $I^{2}=0 \%$ [29]. Administration of oxytocin before versus that after delivery of the placenta did not significantly alter the incidence of severe $\mathrm{PPH}(11 / 58$ versus $14 / 72 ; \mathrm{RR}=0.98,95 \% \mathrm{CI}=0.48$ to 1.98 ; 1 RCT; 130 women) [27]. Prophylactic oxytocin injection (10 IU) in the thigh in non-facility settings versus no injection resulted in no significant difference between the groups $(8 / 682$ versus $1 / 888 ; R R=0.16,95 \%$ $\mathrm{CI}=0.02$ to $1.30 ; 1$ RCT; 1570 women) [51].

\section{Prostaglandin versus placebo}

There was no difference between the groups comparing the routes of administration of misoprostol: oral misoprostol $(400$ to $600 \mu \mathrm{g})$ with placebo (58/736 versus $65 /$ 769; $\mathrm{RR}=0.92,95 \% \mathrm{CI}=0.64$ to $1.33 ; 3 \mathrm{RCTs} ; 1505$ women; heterogeneity; $I^{2}=28 \%$ ) [53], rectal misoprostol $(400 \mu \mathrm{g})$ with placebo $(13 / 270$ versus $19 / 272 ; \mathrm{RR}=0.67,95 \%$ $\mathrm{CI}=0.33$ to $1.39 ; 1 \mathrm{RCT} ; 542$ women) [53], misoprostol (oral or rectal 400 to $600 \mu \mathrm{g})$ with placebo (73/1037 versus 89 / $1075 ; \mathrm{RR}=0.85,95 \% \mathrm{CI}=0.63$ to $1.14 ; 5 \mathrm{RCTs} ; 2112$ women; heterogeneity; $I^{2}=2 \%$ ) [54], oral or sublingual misoprostol $(600 \mu \mathrm{g})$ with placebo $(101 / 2457$ versus $118 / 2457$; $R R=0.92$, 95\% CI $=0.54$ to $1.57 ; 6 \mathrm{RCTs}$; 4914 women; heterogeneity; $\left.I^{2}=66 \%\right)$ [52], oral or rectal misoprostol $(400 \mu \mathrm{g})$ with placebo (61/1526 versus $77 / 1513$; $\mathrm{RR}=0.80,95 \% \mathrm{CI}=0.47$ to 1.37; 5 RCTs; 3039 women; heterogeneity; $I^{2}=58 \%$ ) [52], rectal misoprostol $(400 \mu \mathrm{g})$ with placebo or no uterotonics (13/ 270 versus $19 / 272 ; \mathrm{RR}=0.69,95 \% \mathrm{CI}=0.35$ to $1.37 ; 1 \mathrm{RCT}$; 542 women) [32], sublingual misoprostol $(600 \mu \mathrm{g})$ with placebo or no uterotonics $(0 / 330$ versus $0 / 331$; $R R=0.66$, $95 \%$ $\mathrm{CI}=0.45$ to $0.98 ; 1 \mathrm{RCT} ; 661$ women) [32], buccal misoprostol $(200 \mu \mathrm{g})$ with placebo or no uterotonics $(24 / 173$ versus 22/179; RR $=1.13,95 \%$ CI 0.66 to $1.94 ; 1$ RCT; 352 women) [32], and intramuscular prostaglandin with placebo or no uterotonics $(5 / 22$ versus $10 / 24 ; \mathrm{RR}=0.55,95 \% \mathrm{CI}=0.22$ to 1.35; 1 RCT; 46 women) [32].

\section{Ergot alkaloids versus placebo}

There was no significant difference between the groups comparing oral or intravenous ergot alkaloids with no uterotonics (13/851 versus $27 / 867 ; \mathrm{RR}=0.32,95 \% \mathrm{CI}=0.04$ to 2.59; 2 RCTs; 1718 women; heterogeneity; $I^{2}=74 \%$ ) [33].

\section{Tranexamic acid versus placebo}

Tranexamic acid significantly reduced the incidence of severe $\mathrm{PPH}$ compared to placebo or no treatment (50/882 versus $84 / 872$; $R R=0.49,95 \% \mathrm{CI}=0.33$ to $0.74 ; 4 \mathrm{RCTs}$; 1754 women; heterogeneity; $\left.I^{2}=0 \%\right)$ [56], (16/1051 versus 39/1042; $\mathrm{RR}=0.40,95 \% \mathrm{CI}=0.23$ to $0.71 ; 6 \mathrm{RCTs} ; 2093$ women; heterogeneity; $\left.I^{2}=0 \%\right)$ [59] and (9/703 versus $21 /$ 697; $\mathrm{RR}=0.43 ; 95 \% \mathrm{CI}=0.20$ to $0.94 ; 2$ RCTs; 1400 women; heterogeneity; $I^{2}=0 \%$ [60].

\section{Early versus late cord clamping}

There was no significant difference between the groups for early cord clamping compared to late clamping (34/ 975 versus $37 / 1091 ; \mathrm{RR}=1.04,95 \% \mathrm{CI}=0.65$ to $1.65 ; 5$ RCTs; 2066 women; heterogeneity; $\mathrm{I}^{2}=0 \%$ ) [22].

\section{Uterine massage versus no uterine massage}

There was no significant difference between groups implementing uterine massage prior to placental delivery versus none $(3 / 652$ versus $1 / 639 ; \mathrm{RR}=2.96,95 \% \mathrm{CI}=0.31$ to 28.35; 2 RCTs; 1,291 women; heterogeneity; $I^{2}=$ not applicable) [61].

\section{Effect of interventions using blood transfusion}

We included 18 reviews with blood transfusion as an intervention: four examining active management of the third stage of labour [21, 23, 47, 48], six examining oxytocin use [24, 25, 27-29, 50], two examining prostaglandins [32, 55], one examining ergot alkaloids [33], three 
examining tranexamic acid [58-60], one examining cord clamping timing [22], and one examining uterine massage [61]. Table 5 displays the effect of interventions only compared with placebo or contrasting management.

\section{Active management versus contrasting management}

Active management of the third stage of labour significantly reduced the use of blood transfusions compared to physiological management or expectant management (23/ 2421 versus $72 / 2434 ; \mathrm{RR}=0.32,95 \% \mathrm{CI}=0.20$ to $0.51 ; 3$ RCTs; 4855 women; heterogeneity; $I^{2}=80 \%$ ) [48] and (24/ 2402 versus $71 / 2427 ; \mathrm{RR}=0.35,95 \% \mathrm{CI}=0.22$ to $0.55 ; 4$ RCTs; 4829 women; heterogeneity; $I^{2}=0 \%$ ) [21]. There was no significant difference between the groups for active management, with versus without controlled cord traction: $(68 / 14,024$ versus $71 / 14,038 ; \mathrm{RR}=0.96,95 \%$ $\mathrm{CI}=0.69$ to 1.33 ; 3 RCTs; 28,062 women; heterogeneity; $\left.I^{2}=0 \%\right)$ [47] and $(67 / 13,824$ versus $71 / 13,838$; $\mathrm{RR}=0.94,95 \% \mathrm{CI}=0.68$ to $1.32 ; 2 \mathrm{RCTs} ; 27,662$ women; heterogeneity; $I^{2}=0 \%$ ) [23].

\section{Oxytocin versus placebo}

There was no significant difference between groups that compared oxytocin with placebo (17/1848 versus $15 / 1272$; $\mathrm{RR}=0.89,95 \% \mathrm{CI}=0.44$ to $1.78 ; 3 \mathrm{RCTs} ; 3120$ women; heterogeneity; $I^{2}=0 \%$ ) [29], administration of oxytocin before versus after delivery of the placenta (4/830 versus 6/ 837; $\mathrm{RR}=0.79,95 \% \mathrm{CI}=0.23$ to $2.73 ; 3 \mathrm{RCTs} ; 1667$ women; heterogeneity; $I^{2}=0 \%$ ) [27], and umbilical vein injection of saline plus oxytocin versus saline injection alone $(1 / 37$ versus $0 / 41 ; \mathrm{RR}=3.32,95 \% \mathrm{CI}=0.14$ to $78.97 ; 1$ RCT; 78 women) [25].

\section{Prostaglandin versus placebo}

Oral misoprostol $(400-600 \mu \mathrm{g})$ significantly reduced the need for blood transfusion compared to placebo or no uterotonics $(3 / 1761$ versus $12 / 1758 ; \mathrm{RR}=0.31,95 \% \mathrm{CI}=$ 0.10 to $0.94 ; 5$ RCTs; 3519 women; heterogeneity; $I^{2}=0 \%$ ) [32]. There was no significant difference between the groups that compared buccal misoprostol $(200 \mu \mathrm{g})$ with placebo or no uterotonics $(6 / 550$ versus $9 / 558$; $R R=0.68$, $95 \% \mathrm{CI}=0.24$ to 1.89 ; 2 RCTs; 1108 women; heterogeneity; $I^{2}=0 \%$ ) [32] and that compared oral misoprostol $(600 \mu \mathrm{g})$ with placebo $(1 / 812$ versus $7 / 808$; $R R=0.14,95 \%$ $\mathrm{CI}=0.02$ to $1.15 ; 1 \mathrm{RCT} ; 1620$ women) [55].

\section{Ergot alkaloids versus placebo}

There was no statistical difference in the need for blood transfusion between the ergot alkaloid and no uterotonics groups $(2 / 951$ versus $6 / 917 ; \mathrm{RR}=0.33,95 \% \mathrm{CI}=0.08$ to 1.40; 3 RCTs; 1868 women; heterogeneity; $I^{2}=0 \%$ [33].

\section{Tranexamic acid versus placebo}

Tranexamic acid significantly reduced the incidence of blood transfusion compared to placebo: (15/838 versus 44/824; $\mathrm{RR}=0.34,95 \% \mathrm{CI}=0.20$ to $0.60 ; 6$ RCTs; 1662 women; heterogeneity; $\left.I^{2}=0 \%\right)$ [58], (6/855 versus 26/ 843; $\mathrm{RR}=0.24,95 \% \mathrm{CI}=0.11$ to $0.53 ; 6 \mathrm{RCTs} ; 1698$ women; heterogeneity; $I^{2}=0 \%$ ) [59], and (14/1143 versus 50/1129; $\mathrm{RR}=0.31,95 \% \mathrm{CI}=0.18$ to $0.53 ; 9 \mathrm{RCTs} ; 2272$ women; heterogeneity; $I^{2}=0 \%$ ) [60].

\section{Early versus late cord clamping}

No difference was demonstrated in the need for blood transfusion when early and late cord clamping were compared $(10 / 669$ versus $10 / 676$; $\mathrm{RR}=1.02,95 \% \mathrm{CI}=0.44$ to 2.37; 3 RCTs; 1345 women; heterogeneity; $I^{2}=0 \%$ [22].

\section{Uterine massage versus no uterine massage}

There was no significant difference between groups comparing uterine massage before placental delivery with no massage (4/637 versus $4 / 620$; $\mathrm{RR}=0.97,95 \% \mathrm{CI}=0.26$ to 3.58; 2 RCTs; 1257 women; heterogeneity; $I^{2}=42 \%$ ) [61] and comparing uterine massage before and after placental delivery with no massage (4/735 versus $4 / 722$; $R R=0.97$, $95 \% \mathrm{CI}=0.26$ to 3.58 ; 3 RCTs; 1457 women; heterogeneity; $I^{2}=42 \%$ ) [61].

\section{Discussion}

\section{Summary of main results}

In this overview, we appraised and summarized the evidence from 29 systematic reviews that assessed the effectiveness of prophylactic management of $\mathrm{PPH}$ in the third stage of labour, including caesarean sections. We then summarized review results based on three outcomes: (1) maternal mortality, (2) blood loss greater than $1000 \mathrm{~mL}$, and (3) use of blood transfusion.

\section{Maternal mortality}

There were no effective interventions which we identified. Active management of the third stage of labour with or without controlled cord traction [23, 47], nipple stimulation [62], and prostaglandins [30, 32, 52] were the only interventions that assessed this outcome.

\section{Blood loss greater than $1000 \mathrm{~mL}$}

A few effective interventions were identified: active management of the third stage of labour rather than physiological or expectant management $[21,48]$, administration of oxytocin (5-10 IU) [29], and tranexamic acid versus placebo $[56,59,60]$. A lack of evidence was identified (i.e., no studies found) for the following interventions: fundal pressure versus controlled cord traction as part of the active management of the third stage of labour [49] and intramuscular versus intravenous oxytocin [26]. 


\section{Use of blood transfusion}

The following were effective interventions resulting in reduced blood transfusions: active management of the third stage of labour rather than physiological management [48], active management of the third stage of labour rather than expectant management [21], oral misoprostol $(400-600 \mu \mathrm{g})$ compared to placebo [32], and tranexamic acid compared to placebo [58-60].

\section{Overall completeness and applicability of evidence}

This overview systematically summarized 29 systematic reviews of eight different methods that included pharmacological and non-pharmacological managements; however, this overview had several limitations. We only focused on interventions that compared placebo or contrasting management. In order to make results applicable to practice, broad-based pharmacological interventions compared to other pharmacological interventions should have been included in our main analysis. Maternal mortality was reported in a few reviews [23, 30, 32, 47, 52, 62] (Table 3). Because PPH is one of the leading causes of maternal death, a greater number of reviews examining various interventions are needed to apply findings to clinical settings. Other outcomes had large amounts of data from numerous trials, but most reviews had serious flaws due to high heterogeneity or few outcome events (Tables 4 and 5). This review did not perform sub-group analysis for the delivery mode or setting. Study participants in the included reviews had undergone vaginal delivery or caesarean section, yet none of the reviews identified risk to participants or examined labour interventions. In this overview, we did not show participant details, settings, or interventions. As such, clinicians who wish to apply the evidence from this review to clinical settings should do so cautiously.

\section{Quality of the evidence}

Using the AMSTAR tool [46], we found that the quality of the Cochrane systematic reviews was high; however, non-Cochrane systematic reviews varied from low to high. Only three of 11 non-Cochrane systematic reviews provided the list of included and excluded studies. Providing the list of all studies which appear to meet the inclusion criteria could reduce the risk of publication bias. Most of the systematic reviews in which the quality of evidence was low needed to include a comprehensive research analysis and should have provided details about publication bias.

\section{Potential biases in the overview process}

For this overview, we adopted the method outlined in the Cochrane systematic reviews of interventions [39], which minimized the potential bias introduced at all stages in the review process.
Agreements and disagreements with other studies or reviews WHO has published guidelines for the prevention and treatment of PPH [5]. This document assessed numerous systematic reviews and RCTs that were included in the present overview. The intrapartum guideline, which was published by the National Institute for Health and Care Excellence, assessed active management of the third stage of labour [18]. Several RCTs were included in the NICE guideline despite the omission of a Cochrane systematic review. However, in this overview, we were able to include a broader spectrum of published systematic reviews.

\section{Conclusions}

No effective prophylactic management of maternal mortality was identified. Most methods of effective prophylactic management of $\mathrm{PPH}$ were supported by evidence; however, they were limited to low- or moderate-quality evidence. Higher quality studies are therefore needed. Study participants had undergone vaginal delivery or caesarean section, and their risks and presence or absence of labour interventions were unclear. Therefore, when these prophylactic strategies are used, the state of participants and access to medical care should be considered.

The critical outcome measures about prevention and treatment of PPH are proposed in the WHO guidelines [5]. However, the systematic reviews assessed herein had a variety of outcome measures, as did the individual trials, reducing our ability to compare the results. For example, the outcome regarding the proportion of $\mathrm{PPH}$ had several cut-points (including $\geq 300,400$, and $500 \mathrm{~mL}$ ). This made it difficult to pool results and show all the evidence from similar trials. It is therefore recommended that trials examining preventive interventions for $\mathrm{PPH}$ use consistent outcome measures and those that are recommended in the WHO guidelines [5].

\section{Additional files}

Additional file 1: PRISMA 2009 Checklist. (DOC 68 kb)

Additional file 2: Search strategies for included reviews. (DOCX 22 kb)

Additional file 3: References to studies excluded from this review. (DOCX $16 \mathrm{~kb}$ )

Additional file 4: Risk of bias of reviews [48, 52-54]. (DOCX 88 kb)

\section{Abbreviations}

AMSTAR: A measurement tool to assess reviews; EMBASE: Excerpta Medica database; GRADE: Grades of Recommendation Assessment, Development and Evaluation; MEDLINE: Medical Literature Analysis and Retrieval System Online abbreviations; NICE: National Institute for Health and Care Excellence; PPH: Postpartum haemorrhage; PRISMA: Preferred reporting items for systematic reviews and meta-analyses; WHO: The World Health Organization

\section{Acknowledgements}

The authors would like to thank Dr. Sarah E. Porter for editing and Enago (www.enago.jp) for the English language review. 


\section{Funding}

This work was supported by a grant-in-aid of The YAMAJI FUMIKO NURSING RESEARCH FUND.

\section{Availability of data and materials}

All included systematic reviews are listed in the reference.

\section{Authors' contributions}

YM prepared all parts of the review and data management for the review. YM and KF contributed to selecting studies and the assessment of risk of bias and GRADE. YM and SI made the data collection. YM and YK performed the assessment for quality of included studies. YK commented on the draft review. All authors approved the final manuscript prior to submission.

\section{Ethics approval and consent to participate}

Not applicable for systematic reviews.

\section{Consent for publication}

Not applicable for systematic reviews.

\section{Competing interests}

The authors declare that they have no competing interests.

\section{Publisher's Note}

Springer Nature remains neutral with regard to jurisdictional claims in published maps and institutional affiliations.

\section{Author details}

'Graduate School of Nursing Science, St. Luke's International University, 10-1, Akashi-cho, Chuo-ku, Tokyo 104-0044, Japan. ${ }^{2}$ St. Luke's International University, 10-1, Akashi-cho, Chuo-ku, Tokyo 104-0044, Japan.

Received: 3 August 2017 Accepted: 17 September 2018 Published online: 11 October 2018

\section{References}

1. AbouZahr C. Progress and challenges in women's health: an analysis of levels and patterns of mortality and morbidity. Contraception. 2014. https:// doi.org/10.1016/j.contraception.2014.03.007.

2. AbouZahr C. Global burden of maternal death and disability. Br Med Bull. 2003:67:1-11.

3. Kassebaum NJ, Bertozzi-Villa A, Coggeshall MS, Shackelford KA, Steiner C, Heuton KR, et al. Global, regional, and national levels and causes of maternal mortality during 1990-2013: a systematic analysis for the Global Burden of Disease Study 2013. Lancet. 2014. https://doi.org/10.1016/S01406736(14)60696-6.

4. Say L, Chou D, Gemmill A, Tunçalp Ö, Moller AB, Daniels J, et al. Global causes of maternal death: a WHO systematic analysis. Lancet Glob Health. 2014;2(6):e323-33. https://doi.org/10.1016/S2214-109X(14)70227-X.

5. World Health Organization. WHO recommendations for the prevention and treatment of postpartum haemorrhage. 2012. http://apps.who.int/iris/ bitstream/10665/75411/1/9789241548502_eng.pdf. Accessed 20 Feb 2016.

6. Carroli G, Cuesta C, Abalos E, Gulmezoglu AM. Epidemiology of postpartum haemorrhage: a systematic review. Best Pract Res Clin Obstet Gynaecol. 2008. https://doi.org/10.1016/j.bpobgyn.2008.08.004.

7. Cunningham FG, Leveno KJ, Bloom SL, Spong CY, Dashe JS, Hoffman BL, et al., editors. Labor. Williams Obstetrics. 24th ed. New York: McGraw-Hill; 2014. p. 408-523.

8. Khan RU, El-Rafaey H. Pathophysiology of postpartum haemorrhage and third stage of labour. In: Arulkumaran S, Karoshi M, Keith LG, Lalonde AB, BLynch C, editors. A Comprehensive Textbook of Postpartum Haemorrhage. 2nd ed. London: Sapiens; 2012. p. 94-100.

9. Burbank F. Hemodynamic changes in the uterus and its blood vessels in pregnancy. In: Arulkumaran S, Karoshi M, Keith LG, Lalonde AB, B-Lynch C, editors. A Comprehensive Textbook of Postpartum Haemorrhage. 2nd ed. London: Sapiens; 2012. p. 177-84.

10. Royal College of Obstetricians and Gynaecologists. Postpartum haemorrhage, prevention and management (Green-top Guideline 52). 2011. https://www.ranzcog.edu.au/RANZCOG_SITE/media/RANZCOG-MEDIA Women\%275\%20Health/Statement\%20and\%20guidelines/Clinical-Obstetrics/
RCOG-Prevention-and-management-of-postpartum-haemorrhage.pdf?ext= pdf. Accessed 20 Feb 2016.

11. Baldisseri MR. Postpartum hemorrhage. In: Vincent JL, Abraham E, Moore FA, Kochanek PM, Fink MP, editors. Textbook of Critical Care. 6th ed. Philadelphia: Saunders; 2011. p. 1192-7.

12. Ford JB, Shand AW, Roberts CL. Characteristics, causes and treatment of postpartum haemorrhage in first and second pregnancies. Aust N Z J Obstet Gynaecol. 2013. https://doi.org/10.1111/ajo.12019.

13. Sheldon WR, Blum J, Vogel JP, Souza JP, Gulmezoglu AM, Winikoff B, et al. Postpartum haemorrhage management, risks, and maternal outcomes: findings from the World Health Organization Multicountry Survey on Maternal and Newborn Health. BJOG. 2014. https://doi.org/10.1111/14710528.12636.

14. Fyfe EM, Thompson JM, Anderson NH, Groom KM, McCowan LM. Maternal obesity and postpartum haemorrhage after vaginal and caesarean delivery among nulliparous women at term: a retrospective cohort study. BMC Pregnancy Childbirth. 2012. https://doi.org/10.1186/1471-2393-12-112.

15. Combs CA, Murphy EL, Laros RK Jr. Factors associated with postpartum hemorrhage with vaginal birth. Obstet Gynecol. 1991;77(1):69-76.

16. Magann EF, Lutgendorf MA, Keiser SD, Porter S, Siegel ER, McKelvey SA, et al. Risk factors for a prolonged third stage of labor and postpartum hemorrhage. South Med J. 2013. https://doi.org/10.1097/SMJ. ob013e3182824d1e

17. Suzuki S, Hiraizumi Y, Miyake H. Risk factors for postpartum hemorrhage requiring transfusion in caesarean deliveries for Japanese twins: comparison with those for singletons. Arch Gynecol Obstet. 2012;286(6):1363-7.

18. National Institute for Health and Care Excellence. Intrapartum care for healthy women and babies. 2014. http://www.nice.org.uk/guidance/cg190. Accessed 20 Feb 2016

19. Royal Australian and New Zealand College of Obstetricians and Gynaecologists. Management of postpartum hemorrhage. 2011. https:// www.ranzcog.edu.au/RANZCOG_SITE/media/RANZCOG-MEDIA/ Women\%27s\%20Health/Statement\%20and\%20guidelines/Clinical-Obstetrics/ Management-of-Postpartum-Haemorrhage-(C-Obs-43)-Review-July-2017. pdf?ext=.pdf. Accessed 20 Feb 2016.

20. The Society of Obstetrics and Gynaecologists of Canada. Active management of the third stage of labour: prevention and treatment of postpartum hemorrhage. 2009. http://sogc.org/wp-content/uploads/2013/ 01/gui235CPG0910.pdf. Accessed 20 Feb 2016.

21. Begley CM, Gyte GML, Devane D, McGuire W, Weeks A. Active versus expectant management for women in the third stage of labour. Cochrane Database Syst Rev. 2015;3:CD007412. https://doi.org/10.1002/14651858. CD007412.pub4

22. McDonald SJ, Middleton P, Dowswell T, Morris PS. Effect of timing of umbilical cord clamping of term infants on maternal and neonatal outcomes. Cochrane Database Syst Rev. 2013;7:CD004074. https://doi.org/ 10.1002/14651858.CD004074.pub3.

23. Hofmeyr GJ, Mshweshwe NT, Gülmezoglu AM. Controlled cord traction for the third stage of labour. Cochrane Database Syst Rev. 2015;1:CD008020. https://doi.org/10.1002/14651858.CD008020.pub2.

24. McDonald S, Abbott JM, Higgins SP. Prophylactic ergometrine-oxytocin versus oxytocin for the third stage of labour. Cochrane Database Syst Rev. 2004;1:CD000201. https://doi.org/10.1002/14651858.CD000201.pub2.

25. Mori R, Nardin JM, Yamamoto N, Carroli G, Weeks A. Umbilical vein injection for the routine management of third stage of labour. Cochrane Database Syst Rev. 2012;3:CD006176. https://doi.org/10.1002/ 14651858.CD006176.pub2.

26. Oladapo OT, Okusanya BO, Abalos E. Intramuscular versus intravenous prophylactic oxytocin for the third stage of labour. Cochrane Database Syst Rev. 2012;2:CD009332. https://doi.org/10.1002/14651858.CD009332.pub2.

27. Soltani H, Hutchon DR, Poulose TA. Timing of prophylactic uterotonics for the third stage of labour after vaginal birth. Cochrane Database Syst Rev. 2010;8:CD006173. https://doi.org/10.1002/14651858.CD006173.pub2.

28. Su L, Chong Y, Samuel M. Carbetocin for preventing postpartum haemorrhage. Cochrane Database Syst Rev. 2012;2:CD005457. https://doi. org/10.1002/14651858.CD005457.pub4.

29. Westhoff G, Cotter AM, Tolosa JE. Prophylactic oxytocin for the third stage of labour to prevent postpartum haemorrhage. Cochrane Database Syst Rev. 2013;10:CD001808. https://doi.org/10.1002/14651858.CD001808.pub2.

30. Hofmeyr GJ, Gülmezoglu AM, Novikova N, Lawrie TA. Postpartum misoprostol for preventing maternal mortality and morbidity. Cochrane 
Database Syst Rev. 2013;7:CD008982. https://doi.org/10.1002/14651858. CD008982.pub2.

31. Oladapo OT, Fawole B, Blum J, Abalos E. Advance misoprostol distribution for preventing and treating postpartum haemorrhage. Cochrane Database Syst Rev. 2012;2:CD009336. https://doi.org/10.1002/14651858.CD009336.pub2.

32. Tunçalp Ö, Hofmeyr GJ, Gülmezoglu AM. Prostaglandins for preventing postpartum haemorrhage. Cochrane Database Syst Rev. 2012;8:CD000494. https://doi.org/10.1002/14651858.CD000494.pub4.

33. Liabsuetrakul T, Choobun T, Peeyananjarassri K, Islam QM. Prophylactic use of ergot alkaloids in the third stage of labour. Cochrane Database Syst Rev. 2007;2:CD005456. https://doi.org/10.1002/14651858.CD005456.pub2.

34. du Vigneaud V, Ressler C, Trippett S. The sequence of amino acids in oxytocin, with a proposal for the structure of oxytocin. J Biol Chem. 1953; 205(2):949-57.

35. Ryden G, Sjoholm I. Half-life of oxytocin in blood of pregnant and nonpregnant woman. Acta Obstet Gynecol Scand. 1969;48(Suppl 3):139+.

36. Weeks A, Faúndes A. Misoprostol in obstetrics and gynecology. Int J Gynecol Obstet. 2007. https://doi.org/10.1016/j.ijgo.2007.09.003.

37. Ng PS, Chan AS, Sin WK, Tang LC, Cheung KB, Yuen PM. A multicentre randomized controlled trial of oral misoprostol and i.m. syntometrine in the management of the third stage of labour. Hum Reprod. 2001;16(1):31-5.

38. de Groot AN, van Dongen PW, Vree TB, Hekster YA, van Roosmalen J. Ergot alkaloids. Current status and review of clinical pharmacology and therapeutic use compared with other oxytocics in obstetrics and gynaecology. Drugs. 1998;56(4):523-35.

39. Higgins JPT, Green S (editors). Cochrane Handbook for Systematic Reviews of Interventions Version 5.1.0 [updated March 2011]. The Cochrane Collaboration, 2011.http://www.cochrane-handbook.org. Accessed 25 Sept 2016.

40. Moher D, Liberati A, Tetzlaff J, Altman DG, PRISMA Group. Preferred reporting items for systematic reviews and meta-analyses: the PRISMA statement. J Clin Epidemiol. 2009. https://doi.org/10.1016/j.jclinepi.2009.06.005.

41. BMJ Clinical Evidence. Study Design Search Filters. 2012. http:// clinicalevidence.bmj.com/x/set/static/ebm/learn/665076.html. Accessed 25 Feb 2016.

42. The Nordic Cochrane Centre, The Cochrane Collaboration. Review Manager (RevMan). Version 5.3. Copenhagen: The Nordic Cochrane Centre, The Cochrane Collaboration; 2014.

43. McMaster University (developed by Evidence Prime, Inc.). GRADEpro GDT. GRADEpro Guideline Development Tool [Software]. Hamilton (ON): McMaster University (developed by Evidence Prime, Inc.), 2015. Available from gradepro.org

44. Guyatt GH, Oxman AD, Kunz R, Vist GE, Falck-Ytter Y, Schunemann HJ, et al. What is "quality of evidence" and why is it important to clinicians? BMJ. 2008. https://doi.org/10.1136/bmj.39490.551019.BE.

45. Guyatt GH, Oxman AD, Kunz R, Brozek J, Alonso-Coello P, Rind D, Devereaux PJ, Montori VM, Freyschuss B, Vist G, Jaeschke R, Williams JW Jr, Murad MH, Sinclair D, Falck-Ytter Y, Meerpohl J, Whittington C, Thorlund K, Andrews J, Schünemann HJ. GRADE guidelines 6 . Rating the quality of evidence-imprecision. J Clin Epidemiol. 2011;64(12):1283-93. https://doi.org/10.1016/j. jclinepi.2011.01.012.

46. Shea BJ, Grimshaw JM, Wells GA, Boers M, Andersson N, Hamel C, et al. Development of AMSTAR: a measurement tool to assess the methodological quality of systematic reviews. BMC Med Res Methodol. 2007. https://doi.org/10.1186/1471-2288-7-10.

47. Du Y, Ye M, Zheng F. Active management of the third stage of labor with and without controlled cord traction: a systematic review and meta-analysis of randomized controlled trials. Acta Obstet Gynecol Scand. 2014. https:// doi.org/10.1111/aogs.12424.

48. McCormick ML, Sanghvi HCG, Kinzie B, Mclntosh N. Preventing postpartum hemorrhage in low-resource settings. Int J Gynaecol Obstet. 2002;77(3):267-75.

49. Peña-Martí G, Comunián-Carrasco G. Fundal pressure versus controlled cord traction as part of the active management of the third stage of labour. Cochrane Database Syst Rev. 2007:4:CD005462. https://doi.org/10.1002/ 14651858.CD005462.pub2.

50. Jin B, Du Y, Zhang F, Zhang K, Wang L, Cui L. Carbetocin for the prevention of postpartum hemorrhage: a systematic review and meta-analysis of randomized controlled trials. J Matern Fetal Neonatal Med. 2016. https://doi org/10.3109/14767058.2014.1002394.

51. Pantoja T, Abalos E, Chapman E, Vera C, Serrano VP. Oxytocin for preventing postpartum haemorrhage (PPH) in non-facility birth settings. Cochrane
Database Syst Rev. 2016;4:CD011491. https://doi.org/10.1002/14651858. CD011491.pub2.

52. Hofmeyr GJ, Gülmezoglu AM, Novikova N, Linder V, Ferreira S, Piaggio G. Misoprostol to prevent and treat postpartum haemorrhage: a systematic review and meta-analysis of maternal deaths and dose-related effects. Bull World Health Organ. 2009;87(9):666-77.

53. Joy SD, Sanchez-Ramos L, Kaunitz AM. Misoprostol use during the third stage of labor. Int J Gynaecol Obstet. 2003;82(2):143-52.

54. Langenbach C. Misoprostol in preventing postpartum hemorrhage: a metaanalysis. Int J Gynaecol Obstet. 2006. https://doi.org/10.1016/j.jgo.2005.10.001.

55. Olefile KM, Khondowe O, M'rithaa D. Misoprostol for prevention and treatment of postpartum haemorrhage: a systematic review. Curationis. 2013;36(1):E1-E10.

56. Faraoni D, Carlier C, Samama CM, Levy JH, Ducloy-Bouthors AS. Efficacy and safety of tranexamic acid administration for the prevention and/or the treatment of post-partum haemorrhage: a systematic review with meta-analysis. Ann Fr Anesth Reanim. 2014. https://doi.org/10.1016/.annfar.2014.07.748.

57. Ferrer P, Roberts I, Sydenham E, Blackhall K, Shakur H. Anti-fibrinolytic agents in postpartum haemorrhage: a systematic review. BMC Pregnancy Childbirth. 2009. https://doi.org/10.1186/1471-2393-9-29.

58. Heesen M, Bohmer J, Klohr S, Rossaint R, Van De Velde M, Dudenhausen JW et al. Prophylactic tranexamic acid in parturients at low risk for post-partum haemorrhage: systematic review and meta-analysis. Acta Anaesthesiol Scand. 2014. https://doi.org/10.1111/aas.12341.

59. Novikova N, Hofmeyr GJ, Cluver C. Tranexamic acid for preventing postpartum haemorrhage. Cochrane Database Syst Rev. 2015;6:CD007872. https://doi.org/10.1002/14651858.CD007872.pub3.

60. Ker K, Shakur H, Roberts I. Does tranexamic acid prevent postpartum haemorrhage? A systematic review of randomised controlled trials. BJOG. 2016. https://doi.org/10.1111/1471-0528.14267.

61. Hofmeyr GJ, Abdel-Aleem H, Abdel-Aleem MA. Uterine massage for preventing postpartum haemorrhage. Cochrane Database Syst Rev. 2013;7: CD006431. https://doi.org/10.1002/14651858.CD006431.pub3.

62. Abedi P, Jahanfar S, Namvar F, Lee J. Breastfeeding or nipple stimulation for reducing postpartum haemorrhage in the third stage of labour. Cochrane Database Syst Rev. 2016;1:CD010845. https://doi.org/10.1002/14651858. CD010845.pub2.

Ready to submit your research? Choose BMC and benefit from

- fast, convenient online submission

- thorough peer review by experienced researchers in your field

- rapid publication on acceptance

- support for research data, including large and complex data types

- gold Open Access which fosters wider collaboration and increased citations

- maximum visibility for your research: over $100 \mathrm{M}$ website views per year

At BMC, research is always in progress.

Learn more biomedcentral.com/submissions 